A major purpose of the Technical Information Center is to provide the broadest dissemination possible of information contained in DOE's Research and Development Reports to business, industry, the academic community, and federal, state and local governments.

Although a small portion of this report is not reproducible, it is being made available to expedite the availability of information on the research discussed herein. 


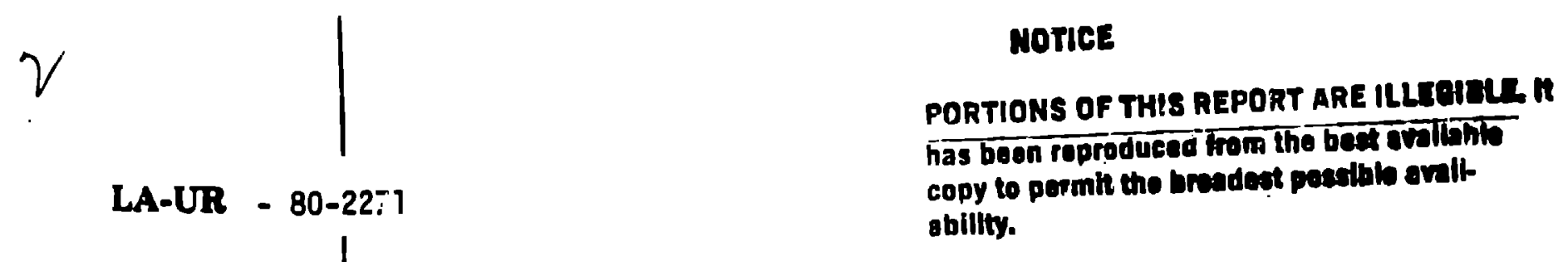

TITLE: LECTURE 5: OISCHARgE CIRCUITS AND LOADS

AUTHOR(S): W. J.. Sarjeant

LA-UR- - 80-2271

DE84 010044

SUBMITIED TO: University of New Mexico

Graduate Course EEC5596

entitled

"HIGH VOLTAGE/PULSE POWER TECHNOLOGY"

and

Los Alamos Scientific Laboratory

E-Division Training Course

entitled

"POWER CONDITIONING TECHNOLOGY"

(Course Coordinator: W. Sarjeant)

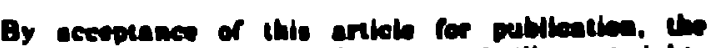

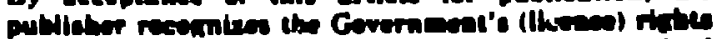
in way copyrtight and the Coverament acd is anthert

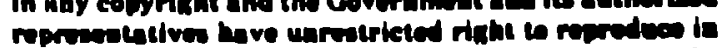

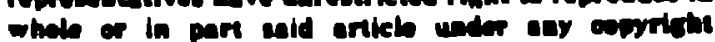
cosured by ine cubltshes.

The La Alames Selowiline Lobaracery naweste that do publioner identin this article as oest performed ucder the auppion of the UACRDA.

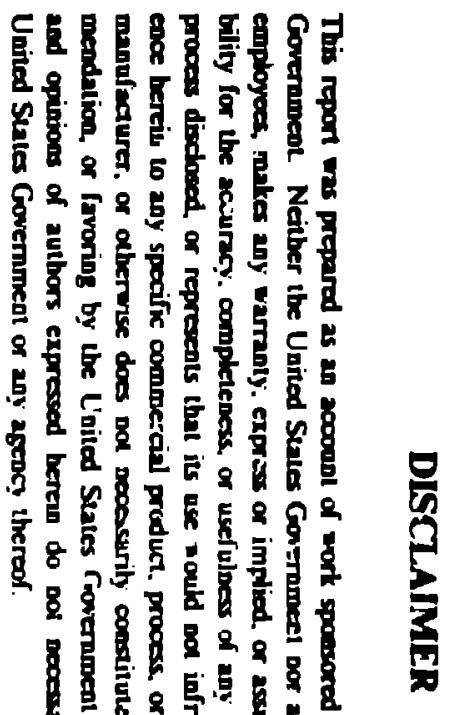

Pmon No, sw

I'VTTHD STATAS

it No.

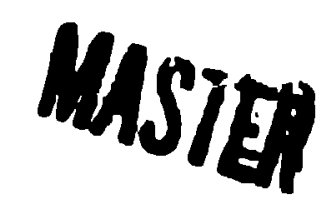

belomilite laborasery

of the Univeralin of Callfornia

los alamos. NAw mixir,o ersa4

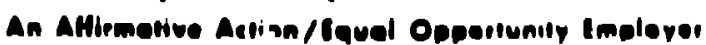

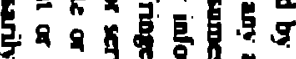

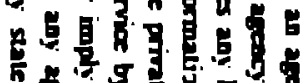

Q दे 5 क 5

$3=8$ 年

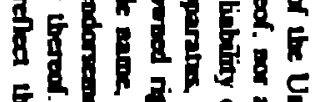

$8=5$

Q

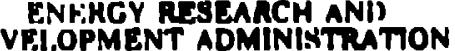
CONTRACT W.740-ENG. 3

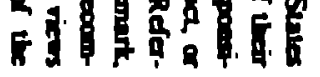


HIGH VOLTAGE/PULSE POWER TECHNOLOGY

GRADUATE COURSF. EECS596

University of New Mexico

LECTURE INDEX

\begin{tabular}{|c|c|c|}
\hline Lecture & Lecture Topic & Instructor \\
\hline 1 & INTRODUCTION TO POWER CONDITIONING . & $\cdots \cdot W_{\text {LASL }}^{\text {J. Sarjeant }}$ \\
\hline 2 & $\begin{array}{l}\text { DC POWER SUPPLIES AND HARD-TUBE POWER } \\
\text { CONDITIONING SYSTEMS }\end{array}$ & R . . W. J. J. Sarjeant \\
\hline 3 & PULSE VOLTAGE CIRCUITS & $\cdots \cdot W_{\text {LASL }}$ L. Willis \\
\hline 4 & TRANSMISSION LINES AND CAPACITORS & $\cdots \cdot$ LASL $_{\text {L. Butcher }}$ \\
\hline 5 & DISCHARGE CIRCUITS AND LOADS & $\cdots \cdot$ H. JASL Sarjeant $^{\text {J. Sar }}$ \\
\hline 6 & $\bullet \cdot \cdots \cdot \cdot \cdot \cdot \cdot$ & $\cdots W_{\text {LASL }}$ L. Willis \\
\hline 7 & THYRATRONS AND IGNITRONS & $\cdots \cdot$ WASL J. Sarjeant \\
\hline 8 & CHARGING SYSTEMS $\cdots \cdots \cdot \cdot \cdots \cdot$ & ... H. WasL C. Nunnally \\
\hline 9 & PULSE TRANSFORMERS ANO DIELECTRICS & $\begin{array}{l}\text {.... G. J. Rohwe in } \\
\text { Sandia Labs }\end{array}$ \\
\hline 10 & MEASUREMENT TECHNIQUES & $\cdots \cdots W_{\text {LASL }}$ L. W1111s \\
\hline 11 & PARTICULAR APPLICATIONS $\ldots \ldots$ & $\cdots \cdots$ R. RSL Butcher $_{\text {LASL }}$ \\
\hline 12 & E-3EPM SYSTEMS $\ldots \ldots \ldots$ & $\begin{array}{l}\text {.... K. R. Prestwteh } \\
\text { Sandia Labs }\end{array}$ \\
\hline 13 & GROUNDING AND SHIELDING TECHNIQUES & .... T. R. Burkes \\
\hline
\end{tabular}




\section{LECTURE 5}

DISCHARGE CIRCUITS AND LOADS

by

W. J. Sarjeant

Los Alamos Scientific Labcratory

October 15, 1y80 


\section{PREFACE}

With the recent increase in technological needs and the interest in the power conditioning arena, one of the problems facing workers in the field is the lack of texts or notes describing recent progress, particularly in the area of repetitive power conditioning. For this reason and because of expanding internal requirements, the University of New Mextco (UNM) and the Los Alamos. Scient if ic Laboratory (LASL) have created a set of lecture notes based upon the graduate course taught recently at UNM. The objective of these notes is to create a record of many of the advances in the ffeld since the last text in the fleld was published just after World War II. In this context, the lectures presented are oriented toward an introduction of the reader to each of the areas described and present suffictent background information to explain many of these advances. They are not intended to serve as design engineering notes, and thus the reader is referred to the references at the end of each lecture for detalled technical information in speciflc areas.

The preparation of these writings is a result of a considerable teamwork effort on the part of LASL and Sandia staff. In particular, Cathy Correl1, in conjunction with Jo Ann Barnes and the rest of her effictent word processing staff, carried the major responsibility for preparation of the lectures while the lecturers did the proofreading and revistons. As course coordinator. it is a pleasure to acknowledge the strong support of Ray Gore, our E-Division Leader, and Shyam Gurbaxani who is the UNM Graduate Center Director, LOS Alanos Campus.

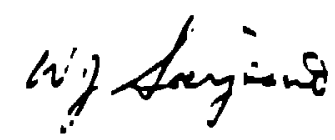

W. J. Sarjeant

Los Alamos Scient if te Laboratory

Los Alamos, New Mexico

October 3, 1980 


\section{LECTURE 5}

\section{Index}

Page

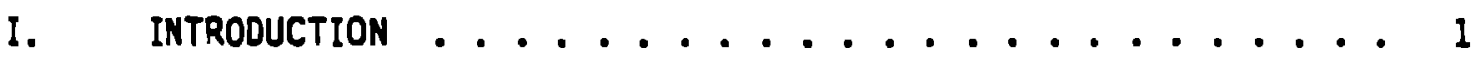

A. General Properties of the Discharge Circuit and Loud .. 1

B. Pulse-Forming Network Systems ........... 3

C. Parasitic Capacitance Effects ........... 7

II. THYRATRONS, IGNITRONS, THYRISTORS, AND THE LIKE . . . . . 7

A. Switch Coimmon Areas .............. 7

B. Thyration Switch Model ........... 7

III. PULSE TRANSFORMERS .................

A. Pulse Transformer Models ............. g

B. Pulse Transformer Limitations........... 12

IV. SWITC' RECOVERY AND RESISTIVE EFFECTS . . . . . . . . 14

V. SWITCH RISETIME EËFECTS IN ULTRAFAST POWER CONDITIONING SYSTEMS . . . . . . . . . . . . . . . 16

A. Swttch Modeling .............. 16

B. Trigger Generator for Multichannel Spark Gaps . . . . 18

VI. EFFECTS OF INTERCONMECTION PULSE CABLES TO LASER LOADS . . 22

VII. EFFECTS OF CHANGE IN THE LOAD IMPEDANCE ON CIRCUIT

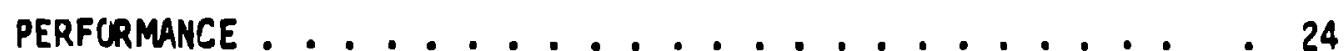

A. Voltage Reversal After PFN Discharge ......... 24

B. Voltage Reversal During Load Faults . . . . . . . . 26

VIII. EFFECT DF PARASITICS ON SYSTEM PERFORMANCE $\ldots \ldots \ldots \ldots$ 
IX. PROTECTING THYRATRONS FROM EXCESSIVE VOLTAGES . . . . . 30

X. EFFECTS OF LOAD SHORT CIRCUITS ............ 33

XI. OPEN-CIRCUIT PROTECTION WITH CABLE INTERCONNECTIONS . . . . 37

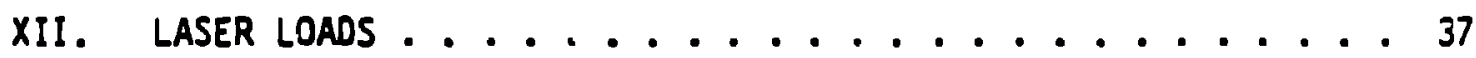

A. Direct-Discharge Pumped Exctmer l.asar Loads . . . . . 37

B. Flashlamp Loads . . . . . . . . . . . . . 43

C. Carbon Dioxtde Laser Load ............ 47

D. Discharge-Pumped Hydrogen Fluor Ide Laser Load...... 49

XIII. SUMMARY ..................... 49

REFERENCES ................. 53 


\section{LECTURE 5}

INOEX TO FIGURES

Flgure

1. General properties of the discharge circuit and loads . . . 2

2. Impedance matching effects on the general properties of the discharge circuit .............. 4

3. Pulse-forming network charactertstics ......... 5

4. Parasitic capacitances and their effects on pulse risetime....................... 8

5. Thyratron switch model .............. 10

6. Puise transfcrmer mudel ............... 11

7. Pulse transformer limitations ........... 13

8. Switch recovery and resistive effacts upon circuit performance ............... 15

9. U1trahigh-speed spark gap trigger generator . . . . . . 17

10. HY-5301 thyratron model and trigger circuit initial

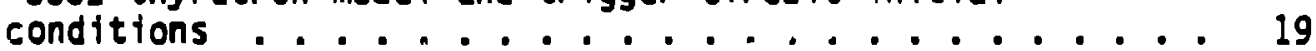

11. Predicted trigger pulse shape using a HY-5301 thyrairon

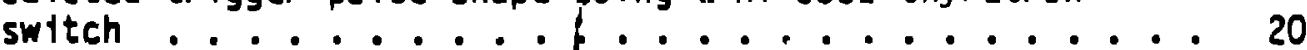

12. Predicted trigger pulse shape using a HY-5323 developmental

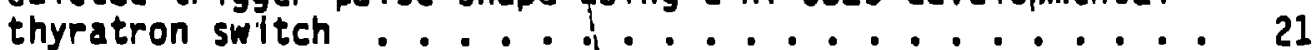

13. Effect of pulse cable between the fast-discharge circult

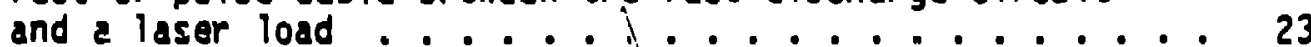

14. Effects of change in load impedance on the performance of line--typs power conditioning systems........ 25

15. Further effects of change in ioad impedance on the performance of itne-type power conditioning systems .... 27

16. (a) Typical line-type PCS ............. 29

(b) Waveforms showing load and thyratron current in a line-type power condittoning system with distrlbuted capacttances ................ 
17. Inverse voltage removal during load faults ........ 31

18. Inverse voltage calculation and removal during load faults . 32

19. Load short-circuit faults . . . . . . . . . . . . 34

20. Inverse voltage appearing during load faults and nonlinear circuits to control this voltage ........... 35

21. Open-circult protection with cable interconnections ..... 38

22. Circuit information for inductive loads ......... 39

23. Simpliffed Excimer laser drtver............ 40

24. Typtcal Exctmer laser ................. 42

25. Time history of cireuit and system parameters in the discl.arge-pumped KrF* laser............ 44

26. Comparison of predicted and measured powers and impedances in the discharge-pumped $\mathrm{KrF} *$ laser ......... 45

27. Flashlamploads ................. 46

28. Carbon dioxide laser loads ............. 48

29. Discharge-pumped hydrogen fluoride laser load .......50

30. Discharge-pumped hydrogen fluoride laser load, cont'd. ... 51

31. Apparent impedance of the discharge-pumped hydrogen

fluoride laser load .............. 52 


\section{LECTURE 5}

DISCHARGE CIRCUITS AMO LOADS

by

W. J. Sarjeant

\section{INTRODUCTION}

This will be an overview in which some of the general properties of loads are examined:

- their interface with the energy storage and switching devices;

- general problems encountered with different types of loads;

- how load behavior and fault modes can impact on the design of a power conditioning system (PCS).

\section{A. General Properttes of the Discharge Circuit and Load}

Consider, In Flgs. 1 and 2, a transmisston line with some impedance $Z_{0}$ and a one-way transit $t$ ime $\delta$, connected in series with an ideal switch, and a load resistor $R_{L}$. Now, $V_{0}$ is the voltage to which the line is charged. When the ideal switch is closed, a current ${ }^{1}$ equal to

$$
\frac{v_{0}}{R_{L}+L_{0}}
$$

flows for a time $\tau=2 \delta$. For this discussion, let us accept this as an experimental fact. The nulse width $\tau$, base to base, is then $2 \delta$ for the case in which the load thi redance equals the impesaince of the transmission itne.

For maximum eneryy transfer it can be shown that there is a relationship between the energy stored in the line and the energy. delivered to the load. There is a broad maximum in the energy transfer effictency (F/g. 1 ). Even with a significant impedance mismatch there can stlll be a quite high transfer of efffeiency in the system. From 0.5 to 1.5 in the ratio of 
FIGURE 1: GENERAL PROPERTIES OF THE DISCHARGE CIRCUIT AND LOADS

General Properties:

- Basic characteristics determined by circuit elements: switch, PFN, and load.

- Pulse cable can introduce some pulse shape degradation, amplitude attenuation, and average power loss.

\section{Ideal Discharging Circuit}

Transmission Line:

(impedance is $z_{0}$ )

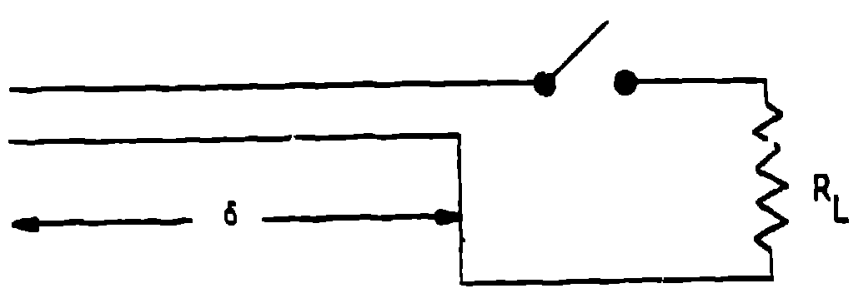

$I(t)=\frac{V_{0}}{R_{L}+Z_{0}} \quad 0<t<2$

$=0 t>2 \delta$ if $R_{L}=Z_{0}$

and $2 \delta \equiv \tau=$ PULSE WIDTH

where $\varepsilon$ is the one-way

transient time.

For Maximum Energy Transfer, $R_{L}=Z_{0^{\circ}}$.

As $R_{L}$ vartes from $Z_{0}$ :

$$
\begin{aligned}
& P_{R_{L}} / P_{Z_{0}}=\frac{R_{L}}{Z_{0}} \cdot\left[\frac{1}{\left(1+R_{L} / Z_{0}\right)^{2}}\right] \\
& P_{L}=\left[\frac{v_{0}^{2}}{\left(R_{L}+Z_{0}\right)^{2}}\right] \cdot R_{L}
\end{aligned}
$$

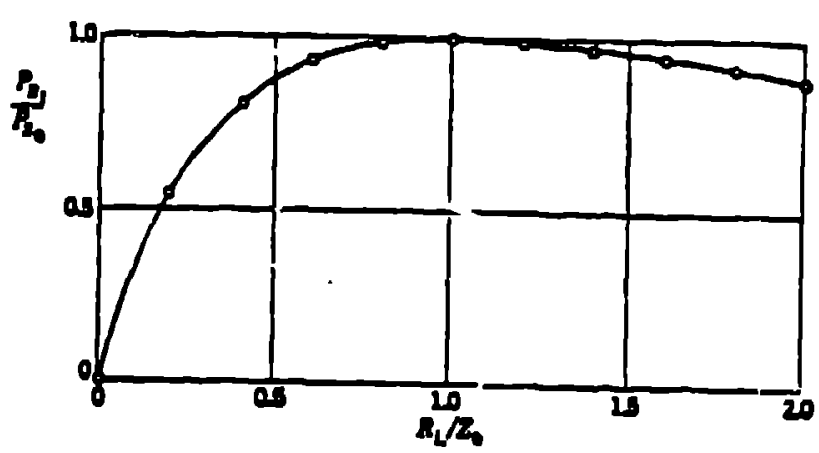


$R_{L} / Z_{0}$, there is $a$ transfer efficiency of about $80 \%$. The real reason, $n$ general terms, that the line impedance is matchej to load impedance is to control the voltage left on the ilne at the end of the discharge cycle. If an 80 to $85 \%$ efficiency is acceptable, there can be a large mismatch.

When the load impedance equals $Z_{0}$, the impedance of the transmission line, the energy stored in the line is one-h-if $C_{0} V_{0}^{2}$ and it is all discharged into the resistive load $R_{L}$ in the same time $\tau$. It can be shown (Fig. 2) that the anergy deposited into the load is the integral of the instantaneous voltage times the current over the discharge time. The discharge time is twice the line capacitance times the line impedance. This is a useful relationship to keep in mind.

The pulse risetime problem in short-pulse duration discharge circuits is due to the parasitic capacitance across the load. The parasitic capacitance times the impedance of the transmission line gives a fairly good measure of what the ultimate risetime will be if the capacitance is fairly large. That is normally the property of the real-world system that degrades the voltage risetime or the lo:d. The current risetime is determined primarily by the inductance in the switch-load interface area.

\section{B. Pulse-Forming Network Systems}

In the case of pulse-forming network (PFN) systems, Fig. 3 shows an example of a system having a unidirectional switch, a type E PFN (of four sections) discharging into an impedance equal to the PFN characteristic linpedance. The PFN discharge current in each section is shown to 11lustrate the different current pulses flowing through the different capacitances in the 11ne. The last caparitor in the line sees twice the peak current. The rms current through each is about the same, but the peak current in the final capacitor is definitely higher. 1 This means that 
FIGURE 2: IMPEDANCE MATCHING EFFECTS ON THE GENERAL PROPERTIES CF THE DISCHARGE CIRCUIT

For $Z_{0}=R_{L}$, all the energy in the transmission ifne is dissipated in $R_{L}$ :

$$
\begin{aligned}
& \text { Let } C_{0}=\text { Line capactiance } \\
& \therefore \frac{1}{2} C_{0} V_{0}^{2}=\frac{V_{0}^{2}}{4 \tau_{0}} \tau=\frac{V_{0}}{2} I_{0} \tau \\
& I . E .=\frac{V_{0}}{2} I \tau=\frac{V_{0}}{2}=\frac{V_{0}}{2 Z_{0} \tau}=\frac{V_{0}^{2}}{4 Z_{0}} \tau \\
& \text { or } \tau=2 C_{0} Z_{0}=\text { Pulse duration }
\end{aligned}
$$

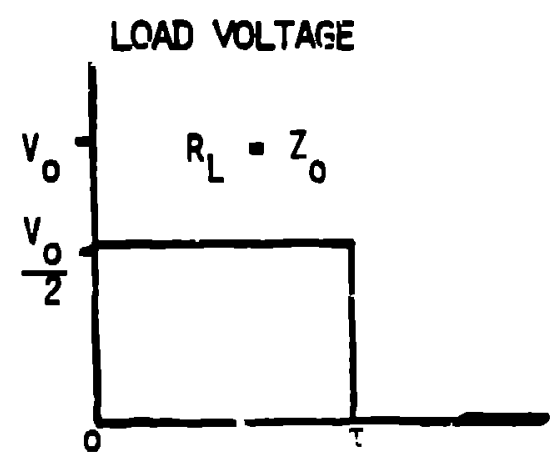

Note that stray capacitances may degrade very short pulse length pulse shapes. 
FIGURE 3: PULSE-FORMING NETHORK CHARACTERISTICS

PFN:

Very fast risetimes and falltimes demand tapered PFNs. Low ripple demands many sections.
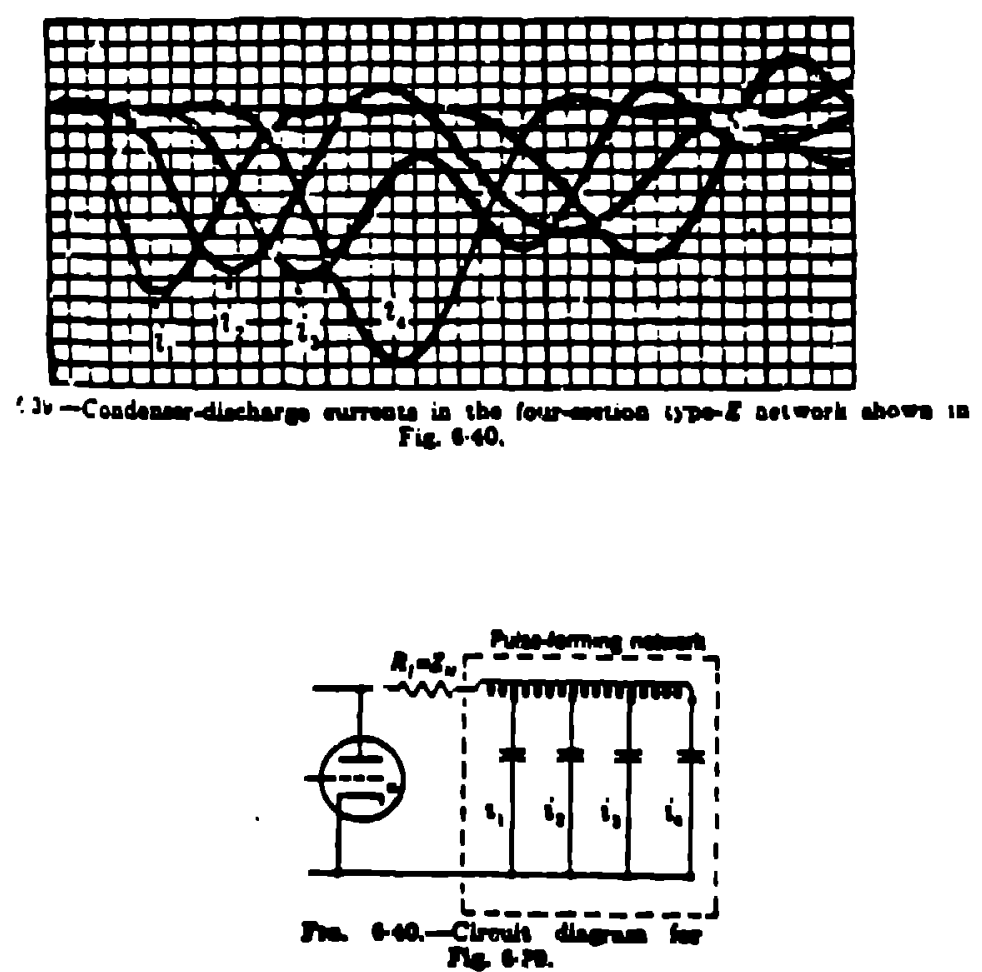

Ref. I

ED53.3\%.EL 
during the design of a PFN it is usually more cost-effective to pruvide the capacitor supplier with a sketch of the network along with the capacitor values and inform him of the load peak current, allowing him to design the capactiors for this service taking into account the current ratios in the varlous PFN capactiors.

For very short-duration current pulses in the multfklloamp range, the PFN capacttor is preferably of the extended-foil type to eliminate internal arcing and tab interface power losses. ${ }^{2}$ If the current risetime required in the load is less than $0.1 \mathrm{t}$, there is a way of achleving this, which was started years ago in gas discharge systems. Giver an ideal switch in a four- to elght-section transmission 11ne, the first four capacitances are selected in the ratio of 1:2:4:8 and the same impedance per section, $z_{0}=\sqrt{L_{N} C_{N}}$. This does not produce a trapezoidal shaped pulse, but it gives a very fast risetime pulse. In this configuration, water vapor lasers were oriven with relatively steep rising current pulses. Because they were direct electron-pumped systems, this increased the electron temperature significantly and increased their laser efficlency. The risetime is effecitvely the discharge time for the very first stage provided the PFNload interface inductance $L$ is small enough so that $L / R_{L}$ is less than the first PFN section discharge timc. This is generally a useful technique for generating a steep wave-front pulse. Time-varyinj load impedances can be roughly matched for these lasers bj setting a ratio for the impedances of $Z_{0}$ to 2:4:8 for the first three sections, creating what is called a tapered transmissien line. This can cause reflecticn problems, but it is a rather uritque and effictent way of driving such loads as hydrogen fluor ide (HF) lasers, $\mathrm{CO}_{2}$ transversely $\mathrm{KrF}$ Excimer systems, whose impedance decreases with time. This is a crude but economical approximation to the general time-varying PFN problem.

For very law ripple on the top of the pulse, there must be many sections in the PFM. A 20-section PFN Can be butlt to have a peak-to-peak ripple of onc per cent, which appears to be a practical 11 mit. It is very difficult to achleve less ripple than this.

EDS380.EL 


\section{Parasitic Capacitance Effects}

A major problem in all these system can be parasitic capacitance and its effects on risetime (Fig. 4). In most cases two of these parasitics predominate: there is one across the switch and there is another across the load. Both are difficult to avoid. The one across the switch is discharged at an extremely high frequency when the switch closes. This could be used to advantage in spark gaps to shorten the resistive phase. The one across the load slows the rate of rise of voltage, creating problems in very fast circuits.

II. THYRATRONS, IGNITRONS, THYRISTORS, AND THE LIKE

\section{A. Switch Common Areas}

This section also discusses tryratrons, ignitrons, thyristors (silicon-controlled rectifiers), or any bulk ionization device where everything is controlled by avalanche ionization and the appropriate analogue in the solid-state case. EG\&G has been studying thyratrons for the Los Alamos Sctentific Letoratcry AP Division to determine the limitations in their switching properties, the maximum speed at which they can be made to switch, and the physical model that correlates with the real world. It turns out that they can be made very fast switches indeed. Ristic shows that in spark gaps, ${ }^{3}$ for the case of nitrogen, the gap voltage decreaies with time and Ristis found a $t^{-3}$ dependence. There is a great deal of discussion about this time dependence and the reader is referred to lecture 6 on Spark Gaps for additional information. 4

\section{B. Thyratron Switch Model}

For thyratrons, a trigger pulse is appiled, there is then an avalanche growth of lectron density forming a glow discharge that may tend towards an abnormal glow for high peak currents. All switches of this class work this way. At $t=0,-V_{0}$ is added than in serles with the switch so that no current flows. As time passes, the voltage source decreases in 
DISCHARGE CIRCUITS AND LOADS

FIGURE 4: PARASITIC CAPACITANCES AND THEIR EFFECTS ON PULSE RISETIME

For most applications, stray capacitances in the power conditioning system fast discharge portion can be lumped into a " $C_{S}^{/}$" at the output of the PFN.

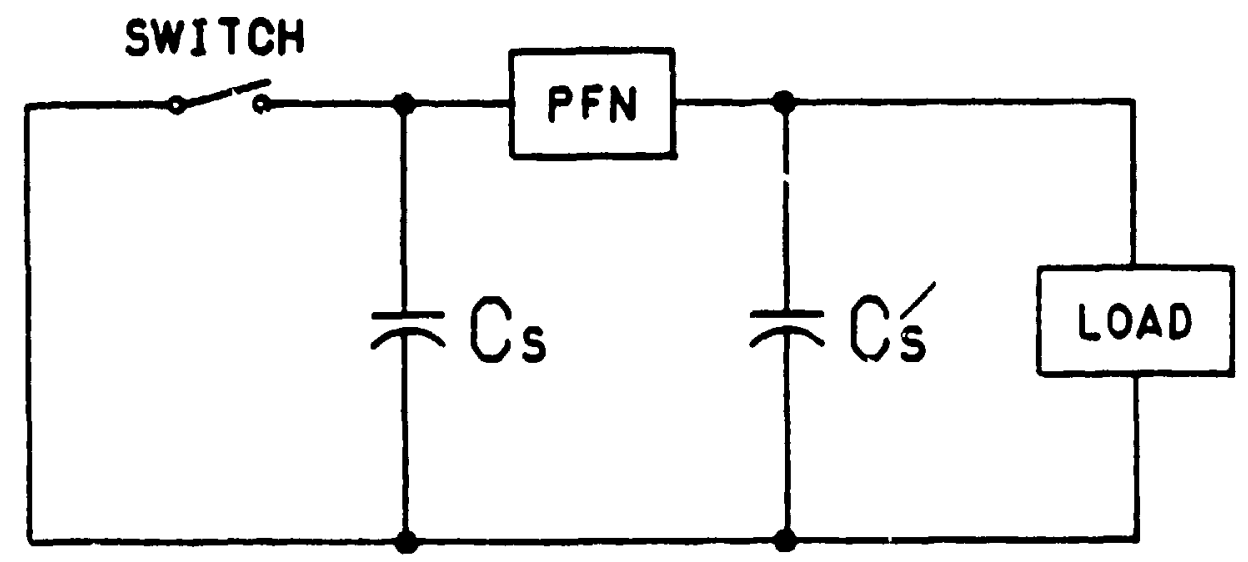

$$
\tau_{r}=z_{P F N} \cdot c_{S}^{\prime}
$$


amplitude and current flows through the system. The current flow is $1 \mathrm{im}-$ ited in its risetime by the lumped inductance $L$, which couples the switch and the load. The voltage drop decreases exponeritially to the constant switch drop level for the duration of the puise. The best values experimentally achieved for. ' $F$ are 1 ns for thyratrs is at klloamp peak current. That is a factor of 10 better than the initial value some 20 years ago. 1

For thyratrons, the medel chat gives very good results in comparison to the data, with the discharge times of 20 to $100 \mathrm{~ns}$, replaces the thyratron with a voltage source ( $F$ ig. 5 ). When the switch is closed, it has a series inductance (from the thyratron and its connections), a voltage source in series with it, plus the switch drop (which is an invariant 100 to $200 \mathrm{~V}$ for almost all gas switches). The $\tau$ that gives the best agreement with the data is, if $\tau_{F}$ is the total falltime from top to bottom, $3 \tau=\tau_{F}$. That gives agreement, within 5 to $10 \%$, with the data for all types of tubes. The examples we shall show later using this model predict somiwhat slower rates of rise than are observed with present thyratron switch tubes.

\section{PULSE TRANSFORMERS}

\section{A. Pulse Transformer Models}

Pulse transformers (Fig. 6), refarring everything to the secondary, have a magnetizing inductance $L_{E}{ }^{\prime}$, a shunt capacitance $C_{C}$, primary to ground converted to seciondary, the secondary-to-ground capacitance $C_{D}$. the leakage inductance $L_{L}$, the core loss $R_{E}{ }^{\prime}$, the load resistance $R_{L}$, and the voltage, $\mathrm{NV}_{0}$. The switch, actually on the primary, is closed with everything referred to the secondary. The diagram then shows an LRC circult with the risetime $L_{L}-C_{D}$ limited.

ED5380.EL 
FIGURE 5: THYRATRON SWITCH MODEL

\section{Most Current Model:}

Let $V(t)$ be the voltage across the switch,

Then:

$$
\begin{aligned}
& V(t)=V_{0}\left(+e^{-t / \tau}\right)+\text { switch drop of }=150 \text { volts } \\
& 3 \tau=\tau_{F}=\text { Resistive phase falltime (i.e., } 100 \text { to } 0 x \\
& \text { voltage falltime) }
\end{aligned}
$$

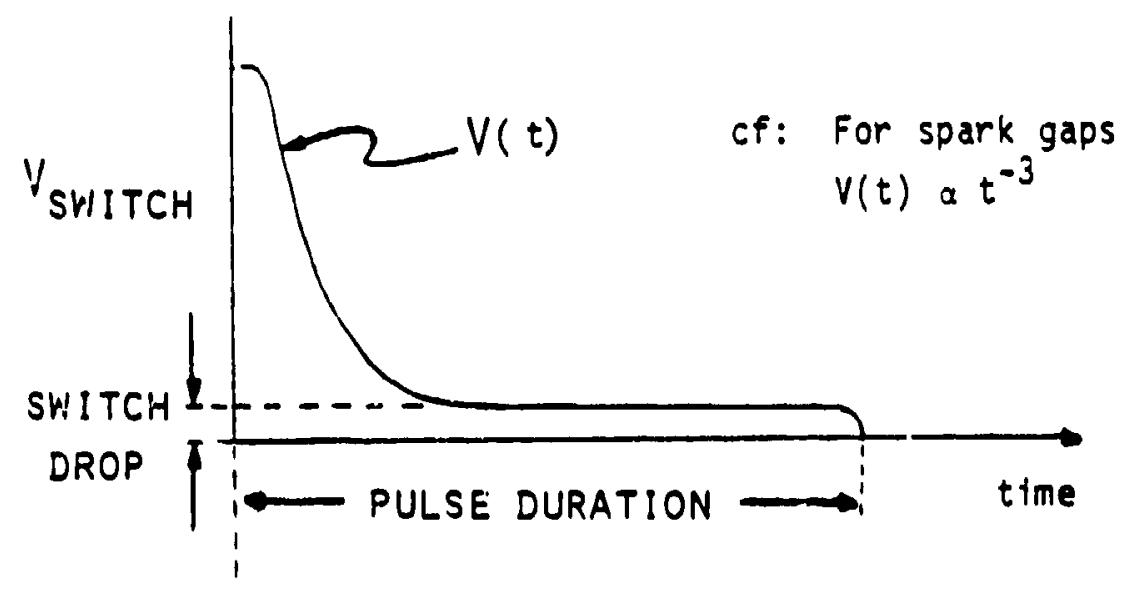

Note: That for most switches the drop is nearly independent of current.

$$
\text { Ret. } 5
$$


FIGURE 6: PULSE TRANSFORMER MODEL.

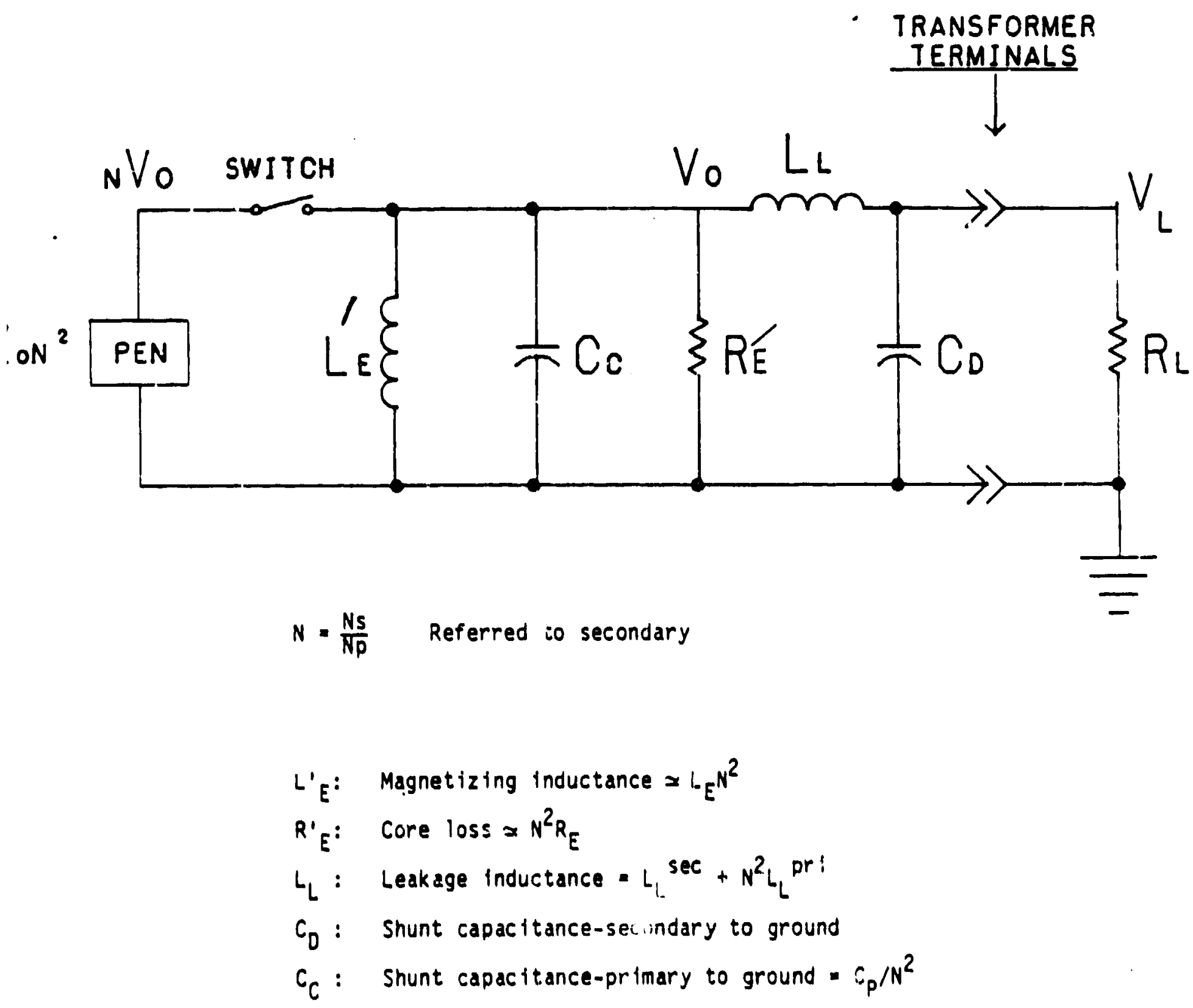


High-pulse fidelity pulse-transformer design is still a compromise of efficiency against pulse fidelity (Fig. 7). Flatness is predominantly controlled by three factors: resonances in the transformer structure, fiux saturation level and the time taken to reach saturation (which is material dependent), and the amount of energy that flows into the magnetizing inductance. For very long pulses, it is the magnetizing inductance that shunts away the desired energy from the PFN. The cost of large, high-qualicy

lse transformers goes up very rafidly with pulse width. Unless absolutely necessary, pulse transformers are an expensive route for pulses ionger than 20 to $25 \mu \mathrm{s}$.

\section{B. Pulse Transformer Limitations}

Given a load like a magnetron or a direct-discharge-pumped gas laser, as the current and the voltage start. to decrease, the sustaining voltage is passed and the current suddenly ceases to flow in the load, except for the current flow in the recharging injuctance or resistance across the load. The falltime limit is then determined by the total locp inductance $L$, which for pulse transformer drive can easily be 400 to $500 \mathrm{nH}_{\text {, }}$ and the Pi: $\mathrm{N}$ impedance, resulting in fairly long falltimes. When a laser switches off, the energy stored in this shunt inductance and in the transformer leakage inductance discharges in a resonant fashion into the inductance/capacitance loop (Fig. 7). Ancther problem is that since this is a resonart discharge there can bu a voltage reversal at the load point. The amount can be determined through a nonlinear analysis for high-power pulse transformers, but it is difficult to do. The amount of reversal is not constant as the load impedance changes. The load and the pulse transformer are int imately interconnected.

For very fast pulses, coaxial cabie transformers can be used to provide voltage gains of two to four times, but they are always rather high impedance. Cable transformers experimentally give much lower multiplications 
FILURE 7: PULSE TR.ANSFORME? LIMITATIONS

\section{Main problem areas $3 r e:$}

1. $\tau_{R}=\pi \sqrt{L_{D} C_{D}}:$ Risetime limit

2. Flatness - determined primartiy by resonances in $L_{L} C_{D}$, and flux "saturat:on" level and time, and energy in $L_{E}$.

3. $\tau_{F}=\pi \sqrt{\left(L_{E}^{\prime}+L_{L}\right) C_{D}}: \begin{aligned} & \text { Falltime limit - especially } \\ & \text { if } R_{L} \text { is biased diode load. }\end{aligned}$

$$
\begin{aligned}
& \approx \pi \sqrt{L_{E}^{\prime} C_{D}} \\
& \text { since } L_{E}^{\prime} \gg L_{L} \text { in generai }
\end{aligned}
$$

4. Reversal depends upon matching and $Q$ of circuit. 
than the theoretical formula predicts. For two or three times, they are an economical way of stepping up voltages. All comments made for the same transformer using ferrite cores to increase permeability also apply to these.

For overali pulser efficiencies, a rough number is about 60 to $80 \%$, which has not changed significantly since the 1940s. A repetition-rate sjistem, even at 1 to $2 \mathrm{kHZ}$ has a given input power of about $70 \%$ of a given sut power for the sysiem. This is due to heat lost in the diodes and

ing unit, and switch losses. This applies to ignitrons, thyratrons, duurr. are devices, and some thyristor (silicon-controlled rectifier) modulators. Spark gaps in repetitive circuits can have quite large losses, and overali system efficiencies can fall well below $60 \%$ at kilohertz repetition rates, 4

\section{SWITCH RECOVERY AND RESISTIVE EFFECTS}

When a load turns off : the current decays towards zero. The resonance effect in all the inductors with the stray capacitances and the recharge circuit tries to put charge back on the PFN. The recovery time for the switch device, whatever it is, is over the time so marked in fig. 8. The area of the first negative pulse represents a positive ion energy deposited inside the thyratron gas switch tube ("gas cleanup"), which can, in effect, increase the heat load on the tube and severely limit the lifetime. ${ }^{1}$ In large, high-repelition-rate systems, where the switch tube is being pushed to the limit of its performance, an enormous amount of positive ion heating of the anode of the tube can occur, easily equaling the anode heating of the tube during the switch turn-on time. A simflar behavior can apply to spark gaps. Energy is deposited in several areas inside the gap unt 11 it fully recovers. Just how importint that is depends on the individual circuit.

ED5380.EL 
DISCHARGE CIRCUITS AND LOADS

LECTURE 5

15

FIGIJRE 8: SWITCH RECOVERY AND RESIST IVE EFFECTS UPON CIRCUIT PERFORMANCE

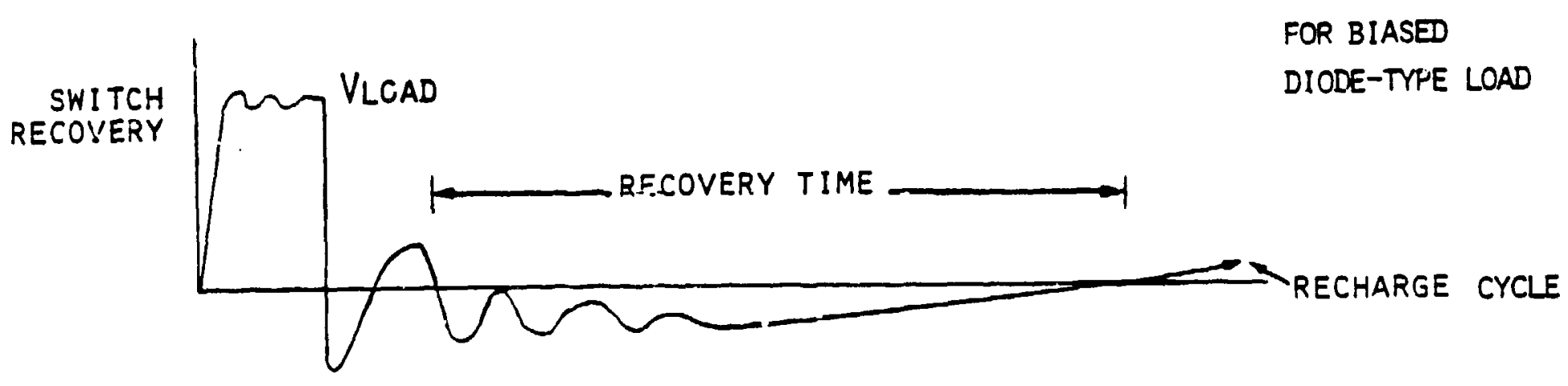

Effect of Switch Resistance:

- Primarily degrades risetime of voltage pulse

ED5330. EL 
FIGURE 9: ULTRAHIGH-SPEED SPARK GAP TRIGGGER GENERATOR

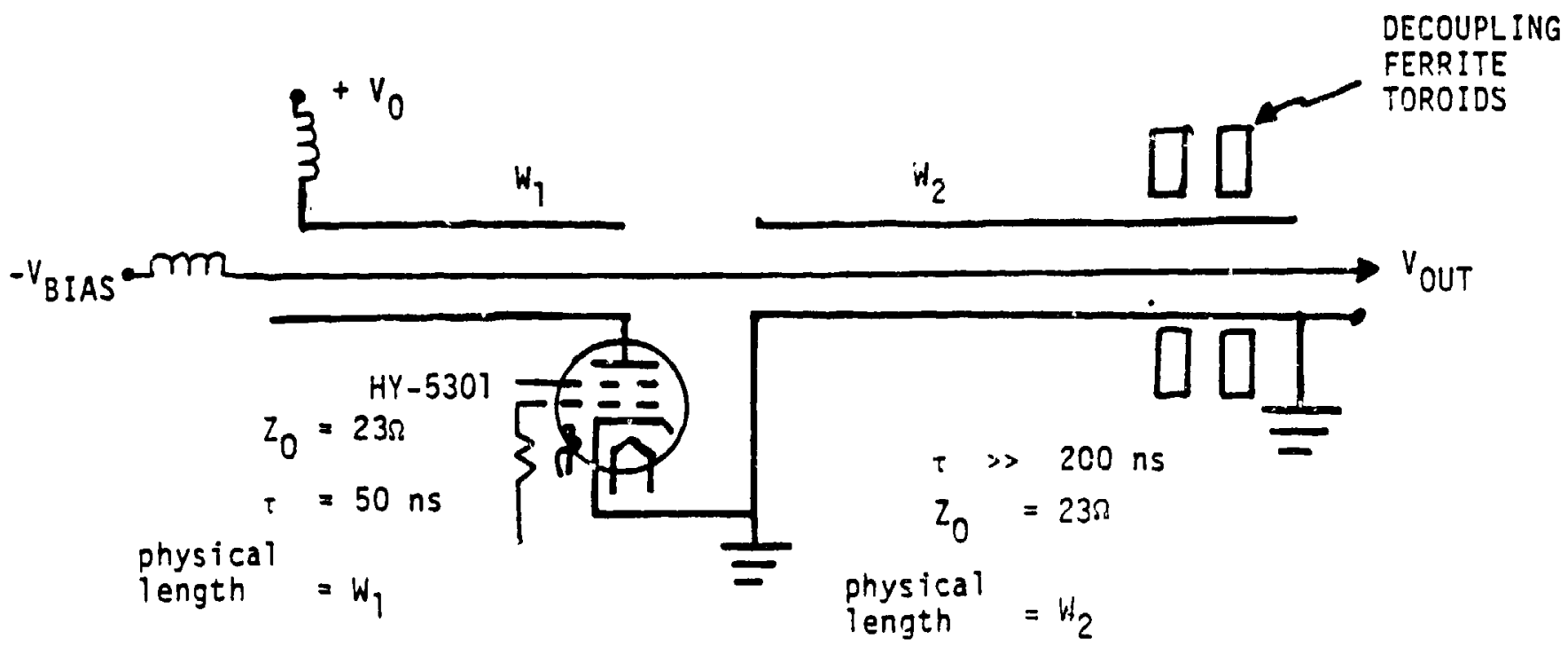

$V_{\text {oui }}$ as a function of time, using NET 2 program and thyratron model as shown in Fig. 5:

For thyratron:

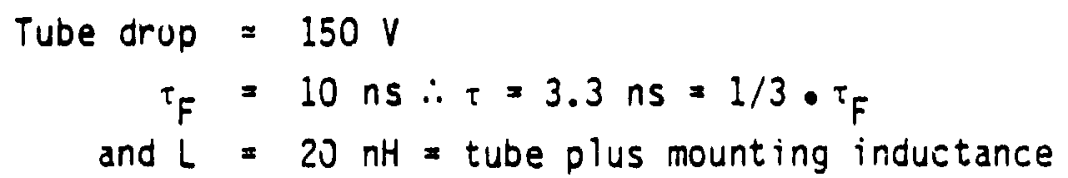

Ref. 5 
V. SWITCH RISETIME EFFECTS IN ULTRAFAST POWER CONDITIONI 'G SYSTEMS

The switch can degrade the risetime. This is illustrated by considering a circuit in Fig. 9 proposed for a mid-plane spark-gap trigger. 5 It is necessary to put a negative bias on the midplane tnrough a coaxial cable. The inductor to the bias line decouples the midplane during the trigger pulse duration. The line of length $W_{1}$ is resonantly charged to voltage $V_{0}$. The switch is closed, which then discharges this line into the second one of length $W_{2}$. There is a negative-going pulse on the second line, and the peak value equals the bias voltage plus the absolute value of $V_{0}$. The particular circuit under consideration has a $23-\Omega 1$ ine, 50 ns long, charging another $23-\Omega$ line The second line, being a long cable, eliminates reflections during the spark gap turn-on phase. The ground current through the coaxial outer conductor is decoupled with ferrite toroids that have been shown to work very well. There are several ferrite tcroids that work particularly well for fast-pulse circuitry (e.g., Ferroxcube type 144T500). About 20 to 30, spaced along tine line, will provide a great dfal of increased shield inductance. They increase the effective ind"sance between the grounds shown to minimize currerit. flow through tis cable during discharge.

\section{A. Switch Modeling}

Bill Nunnally has modeled this with a switch-resistive phase time, $\tau_{F}$, of $10 \mathrm{~ns}, \mathrm{a} \tau$ of $3.3 \mathrm{~ns}$, and a lumped switch plus interconnection inductance of $20 \mathrm{nH} .^{5}$ This is comparable to state-of-the-art systems (Such a thyratron switch tube ir about 1 in. high, and with a current return shroud attached, a total inductance of 10 to $15 \mathrm{nH}$ is measured.) For an ordinary thyratron of conventioral design, which is much larger in size, the inductance can be 200 to $300 \mathrm{iH}$. In the thyratron trigger, for conventional tetrode tubes, $\tau_{f}$ is $\simeq 40 \mathrm{~ns}$ and $80 \mathrm{~ns}$ for triodes. The tube mode 1 is illustrated in Fig. 10. 
Initfally the thyratron is at $+50 \mathrm{kV}$ and the bias on the spark gap at $-50 \mathrm{kV}$. A 50-pF shunt load is assumed across the end of that line. The 23and $50-\Omega$ cables were selected and were found to have little effect on risetime. The switch is a HY-5301, and gives an output pulse (Fig. 11) rate of rise of $7.5 \mathrm{kV} / \mathrm{ns}$, which is more than adequate for multichanneling most spark gaps that require $6 \mathrm{kV} / \mathrm{ns}$. An ordinary thyratron provides only 1.5 to $2 \mathrm{kV} / \mathrm{ns}$. This is, then, a relatively compact switch device that can be used to provide fast trigger systems.

\section{B. Trigger Generator for Multichannel Spark Gaps}

Another tube examined was a developmental 100-kV device (HY-5323), with a $15-n s$ resistive phase falltime and 30-nH total inductance. The advantage of going to the higher voltage is the steeper slope (Fig. 12). For multichanneling, the calculated $11 \mathrm{kV} / \mathrm{ns}$ is more than adequate. This pulse can be generated at repetition rates of several kilohertz with low delay times and extremely low jitter. 
FIGURE 10: HY-5301 THYRATRON MODEL AND TRIGGER CIRCUIT INITIAL CONDITIONS

\section{System Initial Conditions}

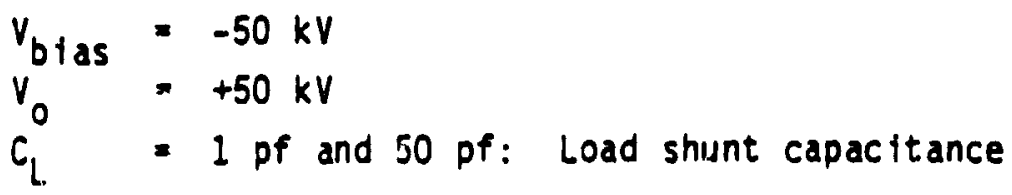

Use thyratrofi model: For HY-5301 tube

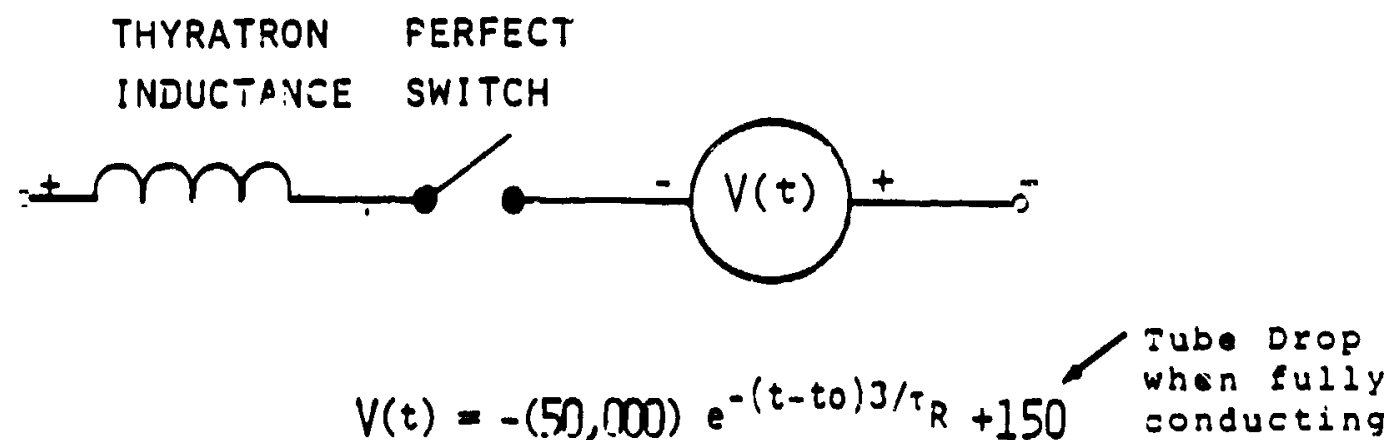

$V_{0}=50,000=$ peak voltage across tube

$20 \mathrm{nH}=$ tube inductance

$t_{0}=t$ ime at which perfect switch is instantly closed

$\tau_{F}=$ resistive phase time for thyratron

$\approx 10$ ns Note: For conventional tudes

$\approx 3^{2}$

$\tau_{F}=40$ ns resulting in some

risetime degradation time

where: is 1/e time

Ref. 5

ED5380.EL 
FIGURE 11: PREDICTED TÁIGGER PULSE SHAPE USING A HY-5301 THYRATRON SWITCH

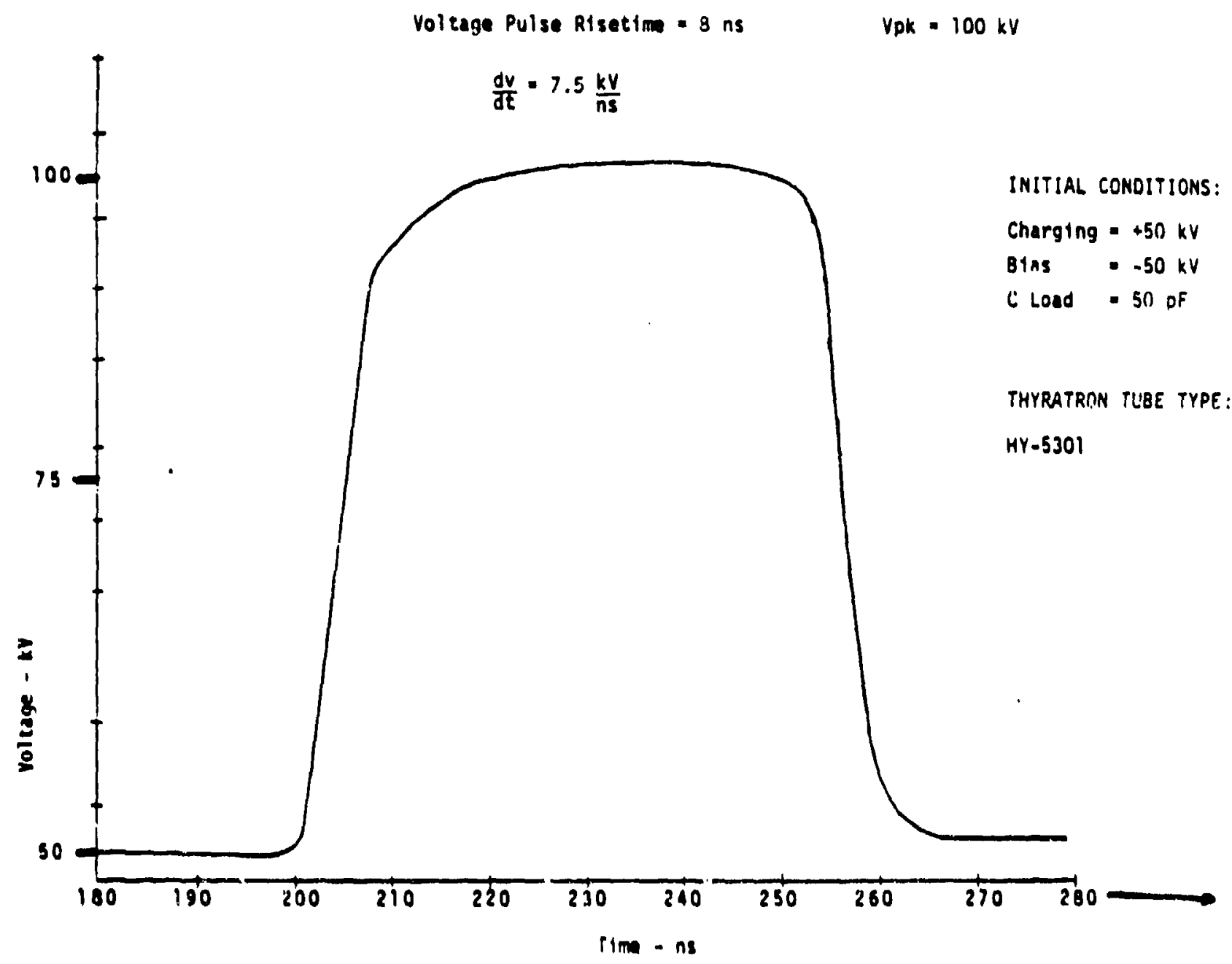

ED5380.EL

Ref. 5 
FIGURE 12: PREDICTED TRIGGER PULSE SHAPE USING A HY. 5323 DEVELOPMENTAL THYRATRON SWITCH

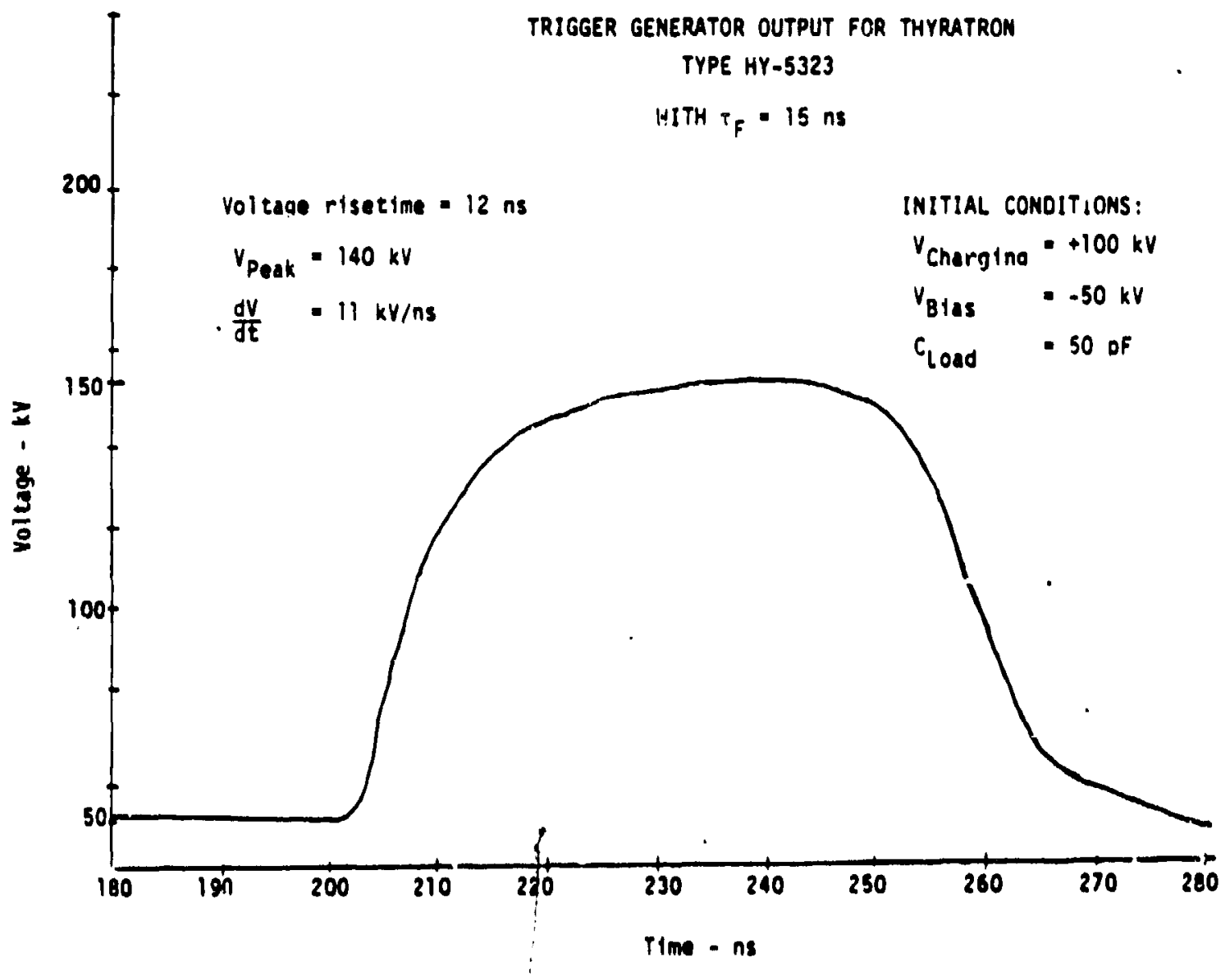

ED5380.EL 
VI. EFFECTS OF INTERCONNECTION PULSE CABLES TO LASER LOADS

There are four points to note on the effects of pulse cables connecting to laser loads (Fig. 13).

1. Given a piece of cable connecting the laser to the pulser, the laser impedance being usually time-varying, reflections can travel back and forth on the cable, causing osclliations on top of the voltage pulse.

2. Coaxial cables are not perfect cables; they have leakage inductances of about $15 \%$ and resistive losses. To derive the same peak power from the system, additional power must be put in the input. To minimize this, special totally shielded cable can be purchased, or high-voltage coaxial cable for underground power distribution systems is readily avallable at less cost and generally works well.

3. When the load faults, an opposite polarity voltage pulse travels back along the cable. Depending on the timing of the fault, enormous voltages can accumulate at the input of the cable. This problem is discussed in detall in Greenwood, ${ }^{6} \mathrm{Ch}$. 3. Generally, if the cable is designed to handle three times the pulse load voltage, faults will not destroy the system. Most faults will not exceed three times the load voltage.

4. For fast pulses of about 1-ns risetime, there is very little current penetration into the conductors. The voltage pulse shape rapidiy degrades substantially as it travels down the cable. The skin effect 1. li discussed in the $b$ k by Metzger and Varbre. ${ }^{7}$ The problem was minimized in one case by keeping the cables shorter than $20 \mathrm{ft}$ for 6-k", 120-ps pulses. One-nanosecond pulses can be piopagated for $100 \mathrm{ft}$ over RG-17 and -19 uncompensated cables. If the cable is kept free of disturbances and physical damage. The fait lift degradation factor is 0.1 and $5 x$, reflection added per run-over. Foam cables are quite good, but should be strung overhead to avold physical damage. (RG-8 foam wfll operate to $6-k V$ pulse at low-repetition rates.) 
FIGURE 13: EFFECT OF PULSE CABLE BETWEEN THE FAST-DISCHARGE CIRCUIT AND a LASER LOAd

For laser loads, pulse cables create:

1. Reflection oscillations on pulse crest

2. Current increases because of cable resistive losses and radiation (intelds not perfect).

3. For load faults, cable can propagate more than $2 V_{0}$ reflections depending upon total eireuft $Q$.

4. For fast pulses ( * nanosecond risetime) skin effect degrades risetime over $\approx 30 \mathrm{~m}$ for RG-17U.

Note that the cable looks like:

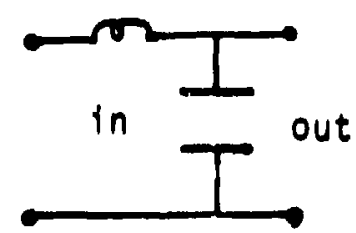

for pulse durations much ionger than 1ts two-way transit time. Then this cable acts as a resonant circuit in conjunction with PFN and/or transforiner stray $C$ and $L$. This can give rise to post-discharge osclllations that may be damaging to the switch or load. Oamping shunt $L-R$ networks in serles with the coaxial cable center conductor at both ends of the cable generally control this. 
In times much longer than the two-way transit time of the cable, a resonant circuit with a series $L$ and a shunt $C$ develops. Pulse discharge oscillations can be dampened in many cases by adding $L / R$ networks in series with the center conductors at both ends of the cable, as will be discussed in detall somewhat later on.

VII. EFFECTS i: CHANGE IN THE LOAD IMPEDANCE ON CIRCUIT PERFORMANCE

Difficulties arise with a time-varying load or one that can have pulse-to-pulse fluctuations (Fig. 14). The TEA $\mathrm{CO}_{2}$ and the Hi lasers have buflt-in fluctuations that are not necessarily repeatable or constant, while vacuum devices like magnetrons and klystrons have almost perfect reproduceability. Many of the flunctuations are caused when the loads arc, posing the problem of protecting the PCS from serious damage.

\section{A. Voltage Reversal After PFN Dijcharge}

An ideal switch discharging a PFN has a charge voltage $V_{N}$, a current through the load, voltage across the load, an impedance $Z_{N}$ (of the PFN) and a load resistance $R_{L}$ on the output. At the end of the discharge time, a voltage can be left on the line. The amount of reversal is $^{1}$

$$
\frac{V_{N-1}}{V_{N}} \cdot \frac{R_{L}-Z_{N}}{R_{L}+Z_{N}}
$$

where $V_{N-1}$ is the peak voltage of the first reversal.

When $R_{L}$ is smaller than $Z_{N}$, which is unfortunately the case for most lasers, thare can be a signiflcant degree of voltage reversal. With a unidirectional switch, the charging circult gra. lly puts current into the PFN and starts recharging. Fundamentally, this negative voltage must be kept within the inverse ratings of the switch device. A typical number for ignitrons is $15 \mathrm{kV}$, for newer thyratrons 15 to $20 \mathrm{kV}$, and for older 
FIGURE 14: EFFECTS OF CHANGE IN LOAD IMPEDANCE ON THE PERFORMANCE OF LINE-TYPE POWER CONDITIONING SYSTEMS

For rapid impedance changes during a puise or pulse-to-pulse varlation, usually caused by load faults, the designer must protect pulser against prolongad short or open circuits in the load loop.

FOR IDEAL PULSER DISCHARGING A PFN OF IMPEDANCE

$Z_{N}$ INTO RESISTIVE LOAD $R_{!}:$

$$
\begin{aligned}
I_{L} & =\frac{V_{N}}{R_{L}+I_{N}} \quad V_{N}=\text { PFN charge voltage } \\
V_{L} & =\frac{V_{N}}{R_{L}+L_{N}} \times R_{L}
\end{aligned}
$$

Voltage left on the network at the end of the pulse is 1

$$
V_{N-1}+\frac{R_{L}-Z_{N}}{R_{L}+Z_{N}} \times V_{N}
$$

$\therefore x$ Voltage Reversal on PFN FOr BIOIRECTIONAL SWITCH: $100 \times \frac{V_{N}-V_{N-1}}{V_{N}}=\frac{2 Z_{N}}{R_{L}+Z_{N}}$

NOTE: For hiased diode load. if $V_{N-1}<V_{\text {threshold }}$ of the load then discharge is through recharge elements in parallel with the load.

Ref. I 
thyratrons $5 \mathrm{kV}$. If this number is exceeded the device arcs. Arc damage depends solely upon the properties of the switch tube. Ignitrons, even at high-repetition rates, can handle some intermittent arcing. Thyratrons usually include protective snubber devices to keep the voltage under control. If the load does arc and it, is a tetrode thyratron tube, basically nothing happens to it because there is the forward bias plasma in the cathode region, and thus when the switch breaks down from excessive inverse voltage, it tends to do so in a bulk ionization mode. Spark gaps of course are fully bidirectional and thus can handle inverse currents with no problem.

If the inverse voltage is less than whatever is needed to turn the load back on in the reverse bias direction, the PFN discharges through the shunt element that is in parallel with the load, which is either the inductor or reststor used to allow the PFN to recharge. The negative voltage just discharges through those elements.

When the load resistance is greater than $Z_{N}$, a step resuits (Fig. 15i. When lasers or magnetrons turn off, the impedance becomes very large and a long time to zero can follow. Spark gaps and ignitrons have no problem handling this, but thyratrons do. 0lder modulators were designed using this positfve mismatch to avold inverse voltage on tubes. It was felt that there must always be a time at which the voltage and current must reach zero to let the tuhe recover. Today, the best way to achieve this goal is to pulse charge the PFN. Instead of only a resonant or resistive charging unit, a switch is put in serles with them and turned an to recharge the PFN well after the output switch has recovered.

\section{B. Voltage Reversa: During Load Faults}

If there is a short-circult fault in the load during the discharge, it ilmost instantaneousily puts $-V_{N}$ across the PFN. If the switch recovers, 
FIGURE 15: FURTHER EFFECTS OF CHANGE IN L.OAD IMPEDANCE ON THE PERFORMANCE OF LINE-TYPE POWER CONDITIONING SYSTEMS

NOTE: $R_{L}<Z_{N}$ case with unidirectional switch: switch opens when voltage across it passes through zerc. Then PFN has $V_{N-1}$ on it at beginning of next charge cycle. For example, in resonant charging:

$V_{N \text { th }}$ charging perfori $n V_{D C}+\left(V_{D C}-V_{J_{N-1}}\right)_{e^{-R} C^{T r} / 2 L_{C}}$

$V_{J_{N-1}}$ - voltage left on PFN after $N-1$ discharge

$$
\begin{aligned}
& T_{r}=\pi \sqrt{L_{L} C_{P F N}} \\
& L_{C}=\text { Charge } L \\
& R_{C}=\text { Loss resistance } \\
& i: i
\end{aligned}
$$

For example, let the load fault with unidirectional switch leaving $-V_{N}$ upon PFi

$$
\begin{aligned}
& \therefore V_{1}=V_{O C}+\left(V_{i C}+V_{N}\right) e^{-\pi / 2 Q} \text { and } V_{N}=2 V_{D C} \\
& \text { If } Q>10 \therefore e^{-\pi / 2 Q=1} \\
& \therefore V_{1}=V_{D C}+\left(V_{D C}+2 \% O C\right)=4 V_{D C} \gg V_{N}
\end{aligned}
$$

GENERALLY SWITCH FAULTS ANO PULSER OL:RVOLTAGE/CURRENT SENSORS TURN HV OFF Cases of interest for PFi charging voltages:

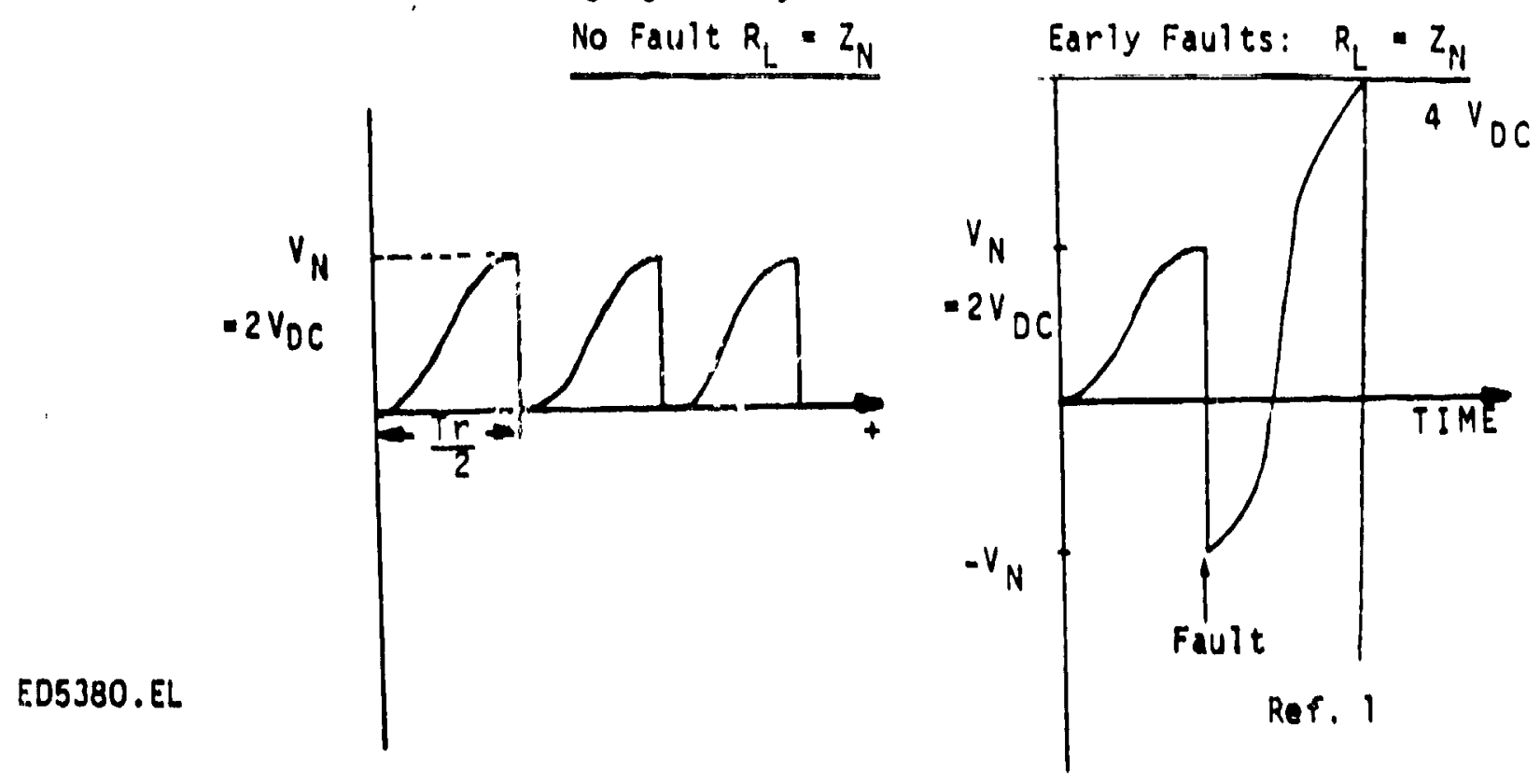


it starts charging from $-V_{N}$ and resonantly charges up to four times the peak dc (Fig. 15). A general property of resonant circuits is that they will charge up to twice the sum of the absolute value of the voltage below the zero line plus the dc voltage. At high voltages, the switch tube faults as it exceeds its forward hold-off voltage, and the protection circuits in the system must come into play.

\section{EFFECT OF PARASITICS ON SYSTEM PERFORMANCE}

A sketch of a typical line-type PCS is given in Fig. 16(a), with several stray capacitances shown. The inverse diode $D_{2}$ is used to clamp any negative voltage ieft on the PFN at the end of the discharge cycle or during load faults. The charging diode is $D_{1}$. The World War II moduiator designs used the vacuum diodes shown, which could be replaced with solid-state diodes. Therc are sti1l, however, stray capacitances. When the switch tube is turned on, $C_{s}$ and $C_{s}$ ' contain stored energy, and being small, force the tube to shunt to ground this energy at a very high rate of rise of current and oscillations occur. In system design, a current-viewing resistor (e.g., T\&M, Inc., Type $W$ ) should always be inserted in the circuit in the cathode of the thyratron, ignition, krytron, etc. (Current transformers are difficult to use in very fast circults: they have a nonGaussian response and give rise to shock-excited oscillations with a driving current waveform that has a front risetime faster than their effective risetime.) If oscillations are apparent, the lifetime of the device in the PCS usualiy will be shortened. During the rapid time-varying resistive turn-on phase, the instantaneous power dissipated in the device can be excesstve.

Oscillations can be dampened with a shunt $L R$ network in the thyratron anode lead. Choose a $Q$ less than 2 if pussible. Ohmite makes a parasitic suppressor used for suppressor grid and neutralization oscillation suppression. It is a 50-8 resistor in parallel with a silver-plated inductor of 0.3-uH inductance and is inexpenstre. They can be used in serles with the anode of the tube and are effective.

ED5380.EL 
FIGURE 16(a): TYPICAL LINE-TYPE PCS

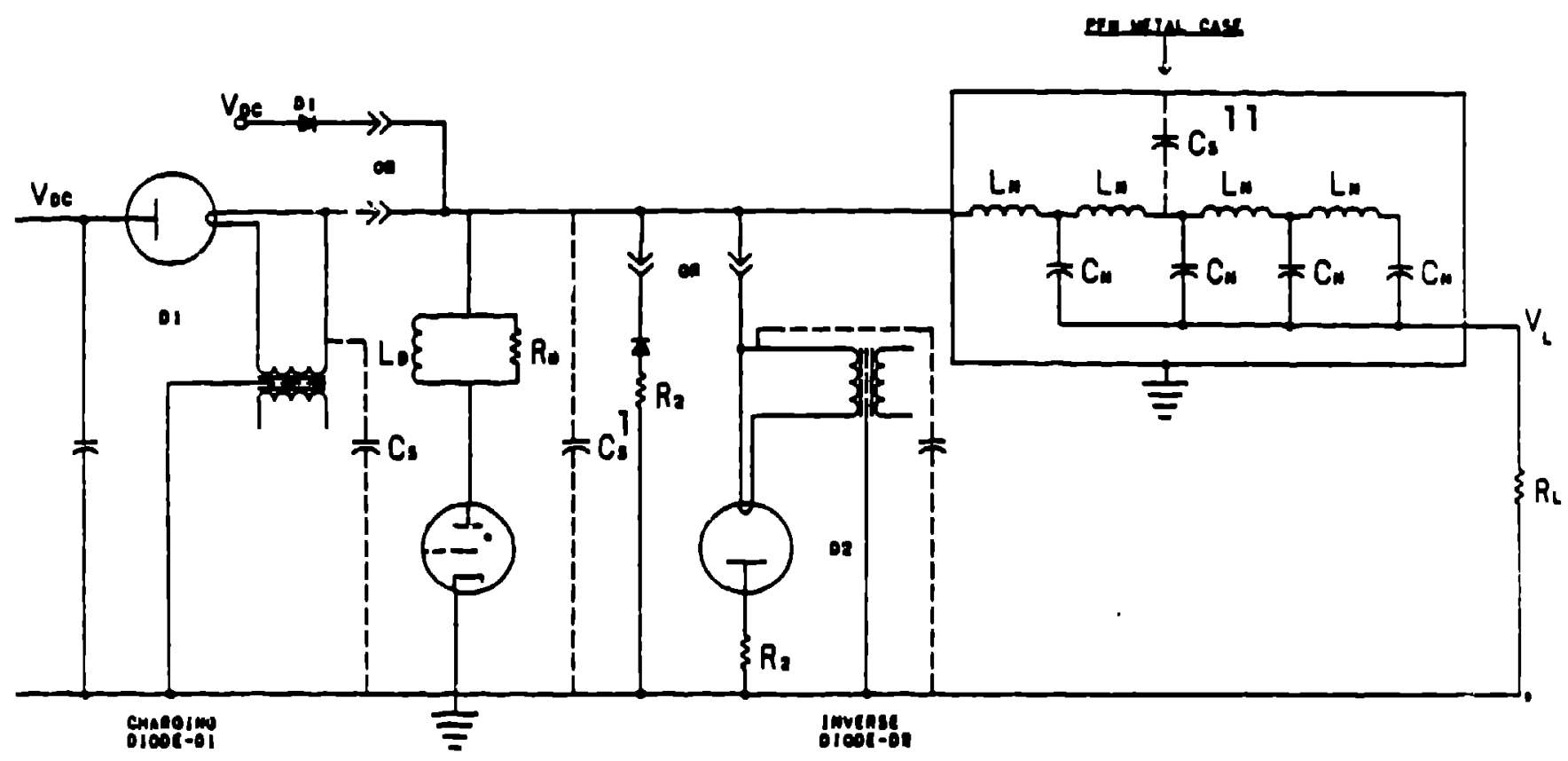

FIGURE 16(b): WAVEFORMS SHOWING LOAD AND THIRATRON CURRENT IN A LINE-TYPE PONER CONDITIONING SYSTEM WITH DISTRIBUTED CAPACITANCES

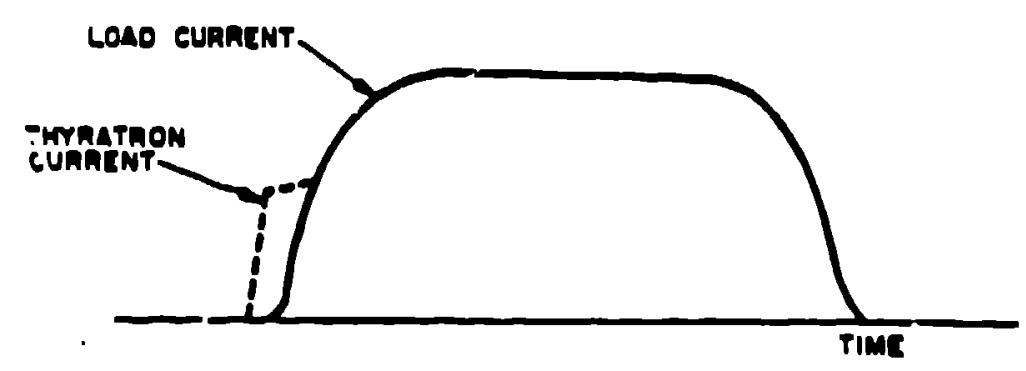

(a)

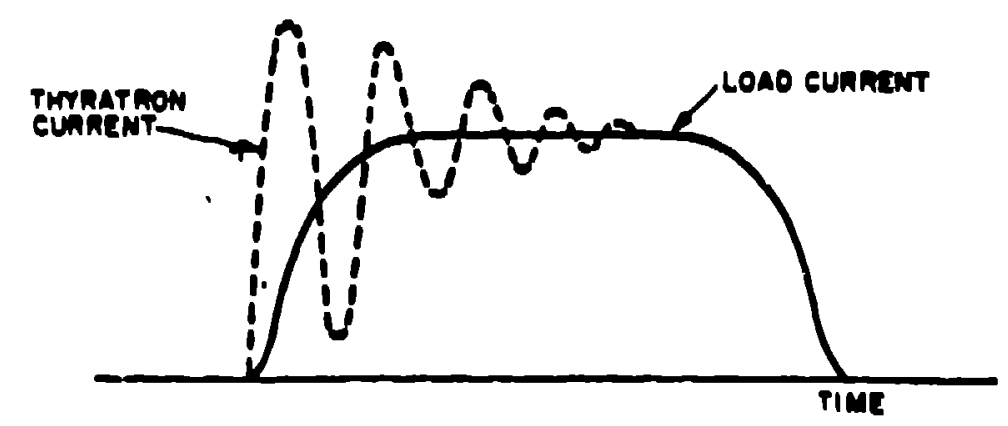

(a)

Ref. 8 
Spark gaps also dissipate power during the turn-on time. That is a waste of the capabilities of the device, and the losses should be minimized by reducing the turn-on time.

\section{PROTECTING THYRATRONS FROM EXCESSIVE VOLTAGES}

If there is a short on the load (Figs. 17 and 18) and if a resistor equal to the impedance of the load could be instantaneously put in parallel with the switch tube, the maximum apparent voltage would be $-v_{d c}$. With a noninductive resistor inserted in the circuit. during a short, a tube charged to +jo kV will see $-25 \mathrm{kV}$ on the anode and the tube could are back. With a tetrode tube, the arc damage from occasional faults is not significant. To really protect the tube a shunt network could be added from anode to ground. Adding a diode-resistor end-of-line clipper across the PFN $\left(R_{0}^{\prime}=z_{0}\right)$, then $12.5 \mathrm{kV}$ will result and the tube will be safe. ${ }^{1}$ The biggest problem is the turn-on time of the diode. Many diodes have fast turn-on times, but are capacitively graded and have very little protection fron stray electromagnetic fields coupling to them and destroying the junctions. For research applications, one means of obtaining fast recovery is to make a coaxial array of very fast recovery diodes and to put them all around the thyratron.

Even if everything is matched a shunt inductor $L_{s}$ not equal to zero is included in the system. When the load is a laser and it turns off with some voltage across it, some current has been flowing through $L_{S}$ at that potnt. A voltage reversal may result, depending upon the ratio of the stored energies in the PFN and the shunt inductance (Fig. 18). Unfortunately, $L_{g}$, the inductance across the load, is usually fairly large to 
FIGURE 17: INVERSE VOLTAGE REMOVAL DLRING LOAD FAULTS

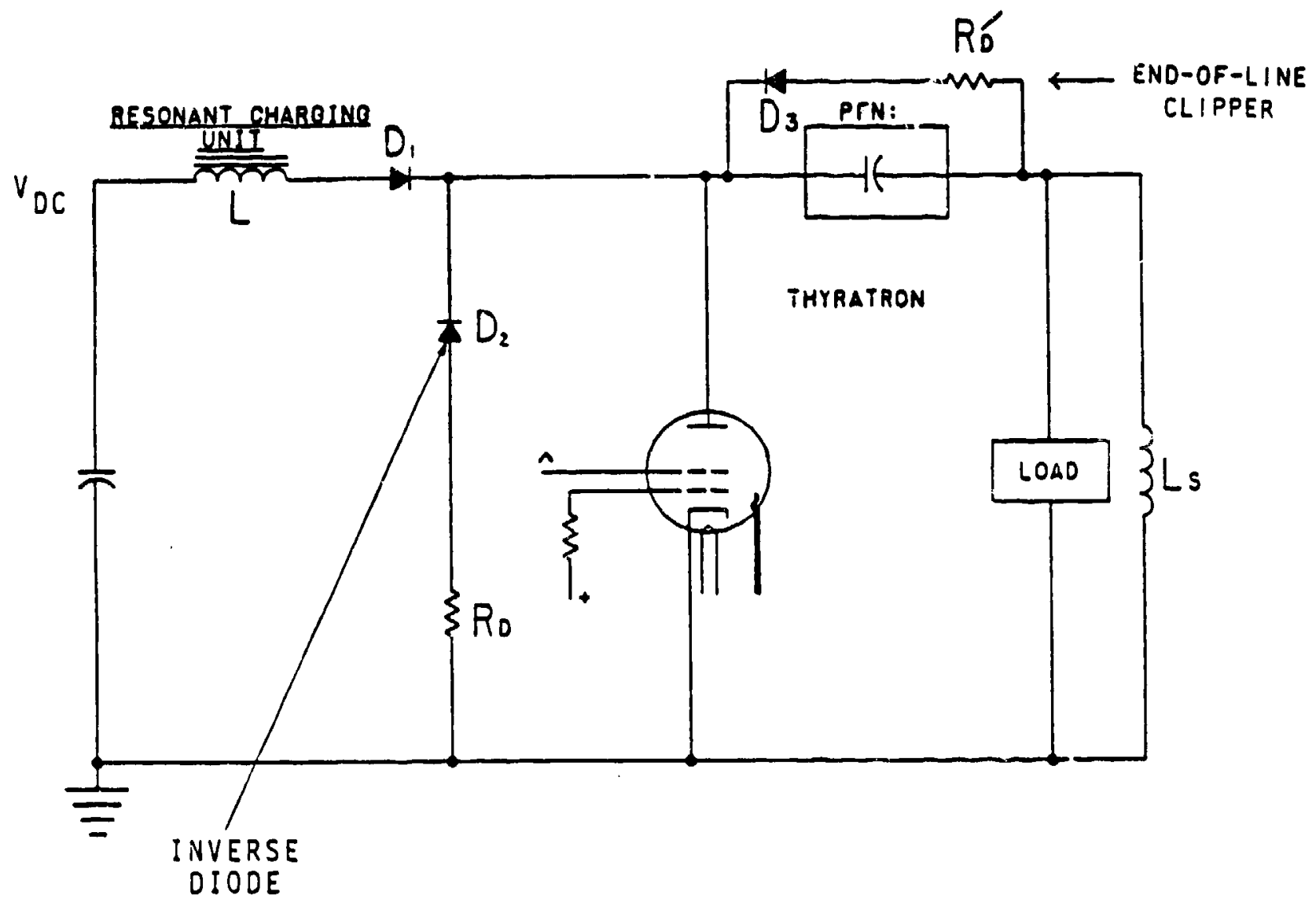

Now the "inverse diode" concucts during fault-induced voltage reversal on PFN, removing PFN voltage to zero before resonant recharging begins. If $R_{D}=Z_{N}=R_{D}^{\prime}$, all voltage, $V_{N-1}$, is removed in thie first reversal pulse.

NOTE: Even for $Z_{L}=Z_{N}$, for $L_{S} \neq 0$ there is some current flow in $L_{S}$, thus at end of pulse:

$$
\begin{aligned}
& i L_{S}=\frac{V_{L}}{L_{S}} \quad \int_{0}^{T} V_{L}=-\int_{S}^{T} \frac{d i}{d t} \\
& V_{L} \Delta T \simeq L_{S} \Delta I \\
& \text { - LSils }
\end{aligned}
$$

Can show: $\frac{V_{N-1}}{L_{N}}=-\sqrt{\frac{L_{P F N}}{T_{S}}}$ and $\Delta T=T$

$\therefore$ may need $\mathrm{D}_{2}$ even if $Z_{L}=Z_{N}$ 
FIGURE 18: INVERSE VOLTAGE CALCULATION AND REMOVAL DURING LOAD FAULTS

At end of pulse of length $t ;$ for laser or magnetron loads, the load open circuits when the voltage is below the holding voltage (Sustaining Voltage) $V_{S}$. Energy stored in $L_{S}$ charges $C_{N}$ capacitance in PFN:

$$
\therefore \frac{1}{2} L_{S}\left(j_{L_{S}}\right)^{2}=\frac{V_{L}^{2} \tau^{2}}{2 L_{S}} \quad j_{L_{S}}=\frac{V_{L} T}{L_{S}}
$$

And $\quad=c_{N} v_{N-1}^{2}$

But since $Z_{N}=Z_{L}$

$$
V_{L}=\frac{V_{N}}{2}
$$

$$
\begin{aligned}
& \therefore C_{N} V_{N-1}^{2}=\frac{1}{8} C_{N} V_{N}^{2}=V_{N}^{2}=\frac{V_{N}^{2} T^{2}}{8 L_{S}} \\
& \left(\frac{V_{N-1}}{V_{N}}\right)^{2}=\frac{\tau^{2}}{4 L_{S} C_{N}^{-}}
\end{aligned}
$$

But $C_{N} V_{N}^{2}=\frac{V_{L}^{2}}{Z_{L}} \tau \quad V_{L}=\frac{V_{N}}{2} \& z_{L}=z_{N}$

$$
\therefore C_{N} V_{N}=\frac{V_{N}^{2} T}{4 L_{L}} \quad Z_{L}=\sqrt{L_{N} / C_{N}}
$$

$$
+2 C_{N} z_{L}=2 C_{N} \sqrt{L_{N} / C_{N}} \cdot 2 \sqrt{L_{N} C_{N}}
$$

$\frac{\therefore\left(\frac{V_{N-1}}{V_{N}}\right)^{2}= \pm \frac{4 L_{N} C_{N}}{L_{S} C_{N}}}{\text { or } \quad\left(\frac{V_{N-1}}{V_{N}}\right)= \pm \sqrt{\frac{L_{N} C_{N}}{L_{S} C_{N}}}= \pm \sqrt{\frac{L_{N}}{L_{S}}}}$

WHERE THF SIGN DEPENDS UPON CURRENT FLOW DIRECTION: e.g., If $I_{L_{S}}$ is the same sign $I_{L}$ was, then negative sign is used since $V_{N-l}$ a $\frac{d I_{L}}{d t}<0$. 


\section{FIGURE 19: LOAD SHORT-CIRCUIT FAULTS}

As we showed in Fig. 15, faulting in the load during discharge can dramatically increase the voltage the PFN is charged to in the following recharge. Only by providing an impedance-matched inverse diode network can this be avoided under all conditions. With present solid-state diodes and hydrogen diodes such a low impedance inverse network is almost always possible.

This network can also be connected across the PFN called an "end-ofline clipper" and serves primarily to clamp the PFN voltage reversal to low value and protect PFN capacitors.
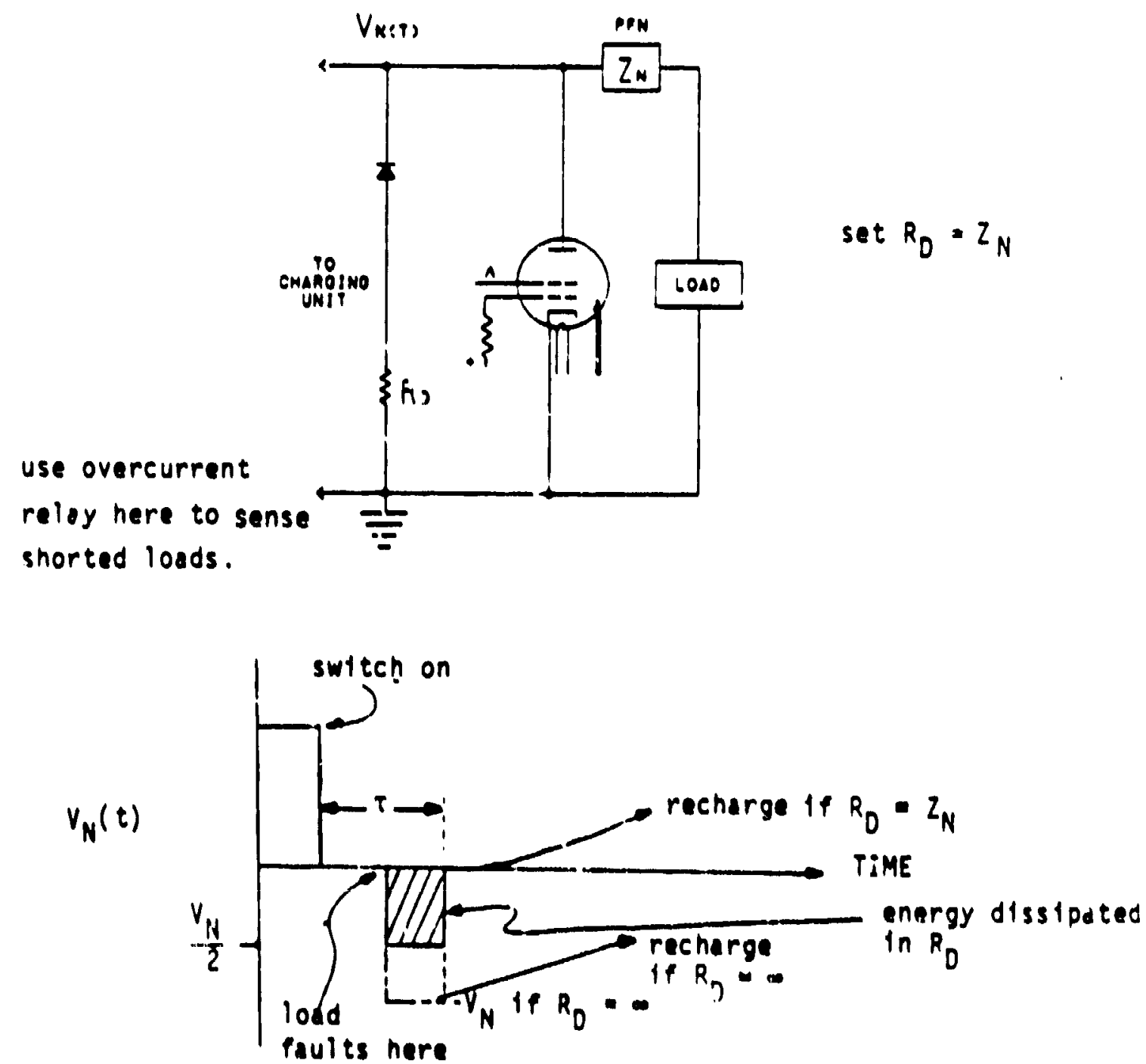

ED5380.EL 
keep the efficiency high; thus, even though the system has perfect matching there may be some need for inverse dlodes to protect the tube from load faults.

The resistor $R_{D}$ is normally quite a large value (several hundreds of ohms) and it is chosen to be large enough to keep the voltage across the switch tube negative unt 11 recovery is assured. For small tubes that can be 2 us, for larger tubes it can be 50 to $250 \mathrm{\mu s}$.

\section{$x$. EFFECTS OF LOAD SHORT CIRCUITS}

Faulting in the load during discharge (Fig. 19) can diamatically increase the voltage to which the PFN is charged in the follow. g recharge. Only by providing an impedance-matched, inverse-diode network can this be avolded under all conditions. With present solid-state dlodes and hydrogen dlodes, such a low-impedance inverse network is almost always possible. These comments pertain specifically to very long-lifetime systems (5 to 10 years) at kllohertz repetition rates with no component fallure desired.

The network, consisting of a dlode and a resistor, can also be connected across the PFN. When it is, it is called an end-of-line cllpper and serves primarlly to clamp the PFN voltage reversal to a low value and protect the PFN capacitors. When the load shorts there is a negativegoing pulse, and the energy represented by the hatched area under the curve is deposited in $R_{D}-Z_{N}$, and recharge then occurs. $R_{D}$ should be slightly smaller than $Z_{N}$ so that sufficlent negative voltage recovery time is avallable.

Note that the switch st 111 must hold off $V_{N} / 2$ during the remainder of the discharge time (Fig. 20). Normally, restrikes of the switch will occur infrequently during these conditions. Adding an end-of-line clipper reduces the voltage by another factor of 2, clamping the PFN revorsal to

ED5380.EL 
FIGURE 20: INVERSE VOLTAGE APPEARING DURING LOAD FAULTS AND NONLINEAR CIRCUITS TO CONTROL THIS VOLTAGE

NOTE: The switch still must hold off $-V_{N} / 2$ during the remalnder of the time $\tau$. Normally restrikes of the switch occur infrequently during these conditions. Adding an "end-of-line clipper" reduces the voltage by another factor of 2, clamping the PFN reversal to $\propto V_{d c} / 2$. With fast circuitry they are "often replaced" and an inverse dlode network only is used.

NOTE: True tetrode thyratrons are highly damage rasistant to inverse internal arcing. They should be used whenever posstble.

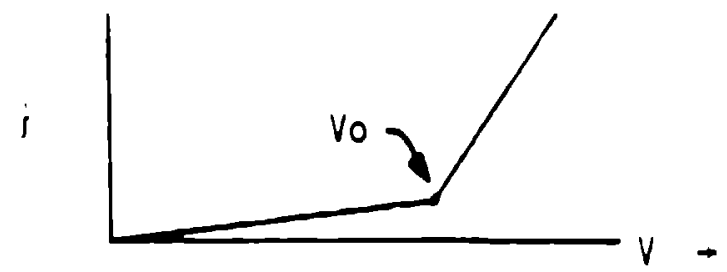

NONLINF.AR CIRCUITS: The "mov" and "thyr tte" matertals have I a $(V-V)^{6}$ so that they can replace all or a portion of $R_{D}$ to reduce diode $\frac{d f}{d t}$ and allow larger peak currents:

$$
\begin{aligned}
\frac{d 1}{d t} & <3 \frac{K A}{M S} \text { (Westirighouse } 20 \text { A stacks) } \\
& <1 \frac{K A}{M S} \text { (Westinghouse } 5 \text { A stacks) }
\end{aligned}
$$

- CONSULT MFR FOR PEAK CURRENT LIMITATIONS: Generally $I^{2}$ pk t energy $11 \mathrm{mit}$ 
less than $V_{d c} / 2$. With fast circuitry, they fall rather frequently and an inverse dlode network only is used.

What is normally meant by tetrode thyratrons is an anode, a control grid, a cathode structure, and an envelope with some hydrogen inside. Normally, there is a tiny pin stuck in the side of the grid structure, when forward blased, will redice the jitter. That is not a tetrode tube; chat is a tube that has a prefonizer electrode in it. This tube otherwise behaves like an ordinary trlode thyratron. A true tetrode thyratron actually contains another grid. An electron cloud is generated through forward blasing this first grid, and the potentlal well from the reverse-blased upper grid prevents these electrons from seeing the accelerating anode potential. Note that true tetrode (with two grids) thyratrons are highly damage resistant to inverse internal arcing. They should be used whenever possible.

In a large reliable system, fault current should be controlled with an inverse network. Current could be put through a time-varying resistor to keep the inverse voltage initially low and gradually discharge the PFN, reducing premature fallure. This can be done with thyrite varistors. They are highly capacitive and difficult to use in kilohertz repetition-rate circuits.

The matal-oxide varistor and thyrite materials have 1 a $\left(V-V_{0}\right)^{6},\left(V_{0}\right.$ is the turn-on voltage and $V$ the applied voltage) so that they can replace all or a portion of $R_{D}$ to reduce $d t / d t$ and stlll allow larger peak current3. Keeping $d 1 / d t$ less than $3 \mathrm{kA} / \mathrm{\mu s}$ for $20-\mathrm{A}$ stacks and about $1 \mathrm{kA} / \mathrm{ms}$ for 5-A diode stacks is recormended by Westinghouse.

EDS380.EL 


\section{OPEN-CIRCUIT PROTECTION WITH CABLE INTERCONNECTIONS}

Referring to Fig. 21, If the load is shorted, a wave is sent back and is multiplied repeatedly unt 11 the cable breaks down. If $L$ and $R$ are correctly chosen, the voltage pulse can be reduced signiflcantly. In large systems with very high voltages there is no choice but to do this. In singleshot systems, a single point-plane spark gap connected to ground through a copper sulphate resistor is used to offer additional protection. If the laser faults, it sends back $a-V$ and the point-to-pline gap across the cable input breaks down controlling this voltage. Such spark gaps can be used for high repetition rate systems, hut erosion and gas flow needs may pose problems. In another circult, the switch can be self-triggered. If relatively long pulses are used, a triggered spark gap protector can be added. When the wave comes back, a capacitive divider reduces the voltage and, fed through a dtode, triggers the spark gap.

For cable connections to the load, etther a shunt spark gap to ground or a shunt $L / R$ network at each end of the cable is suggested to protect from overvoltages.

Figure 22 is a useful compllation of information on inductive loads prepared by $B 111$ Nunnally.

XII. LASER LOAOS

\section{A. Oirect-01scharge Pumped Excimer Laser Loads}

Rare-gas halogen lasers, of constderable interest as sources of intenso ultraviolet energy, represent one of the most challenging timevarying loads to come into existence in the last decade (F1g. 23). One of the difficulties in these systems is their time-varying nature. 
FIGURE 21: OPEN-CIRCUIT PROTECTION WITH CABLE INTERCONNECTIONS

For cable connections to the load, use a shunt spark gap to ground or a shunt $L / R$ network at each end of cable to protect from overvoltages.

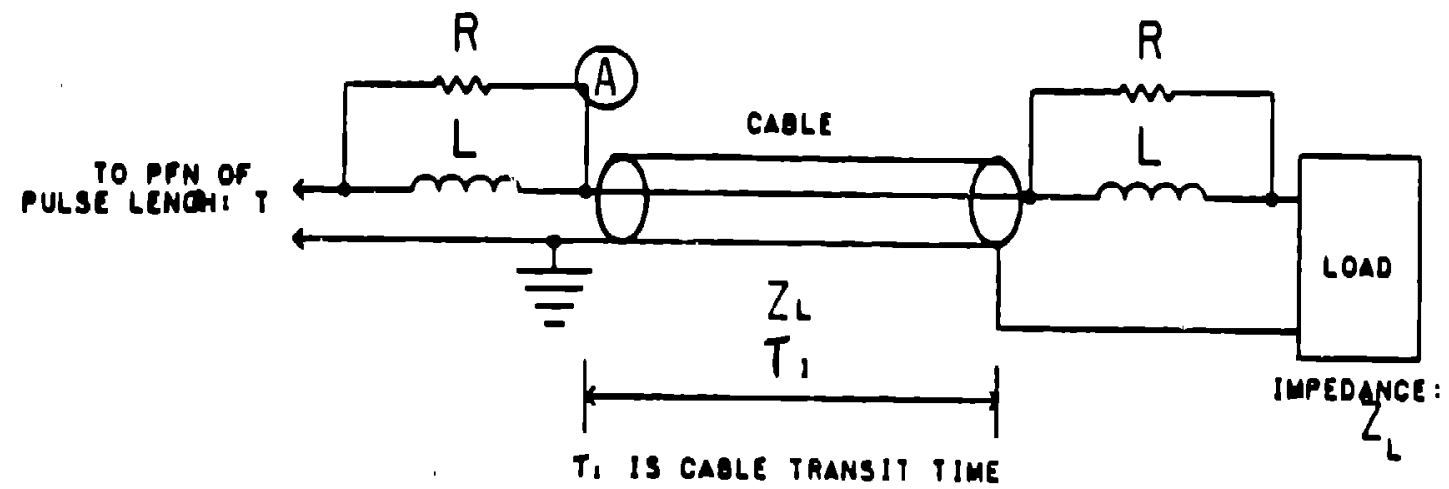

$L / R<\tau_{R}$ AND $L / R \gg 2 \tau_{1}$ for proper damping. If $L / R=2 \tau_{1}$ then at time t. - $2 \tau_{1}$ voltage at $\left(A\right.$ is a $\left(e^{-L / R} \cdot{ }^{t}\right) V_{N} / 2$

For load shorted: $V^{-}-V_{N} / 2 \times\left|1 / e^{2}\right|\left(1 . e ., 90 \%\right.$ damping) pick $Q=\frac{w L}{R}=0.5$ to quench osclllations; therefore voltage stress at (A) has been reduced from $2 v_{N}$ to $.05 v_{N}$ and only small oscillations are allowed. 
DISCHARGE CIRCUITS AND LOADS

LECTURE 5

39

FIGURE 22: CIRCUIT INFORMATION FOR INDUCTIVE LOADS

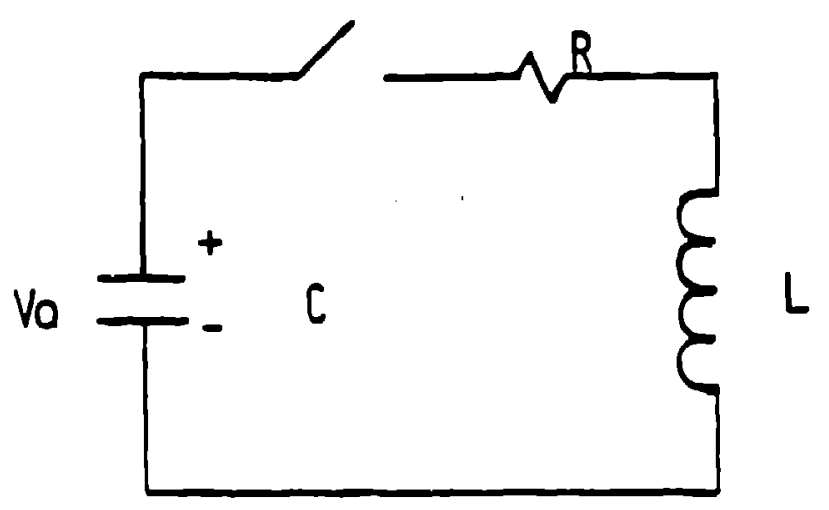

$$
\frac{R}{2 L} \ll\left(\frac{1}{L C}\right)^{k}
$$

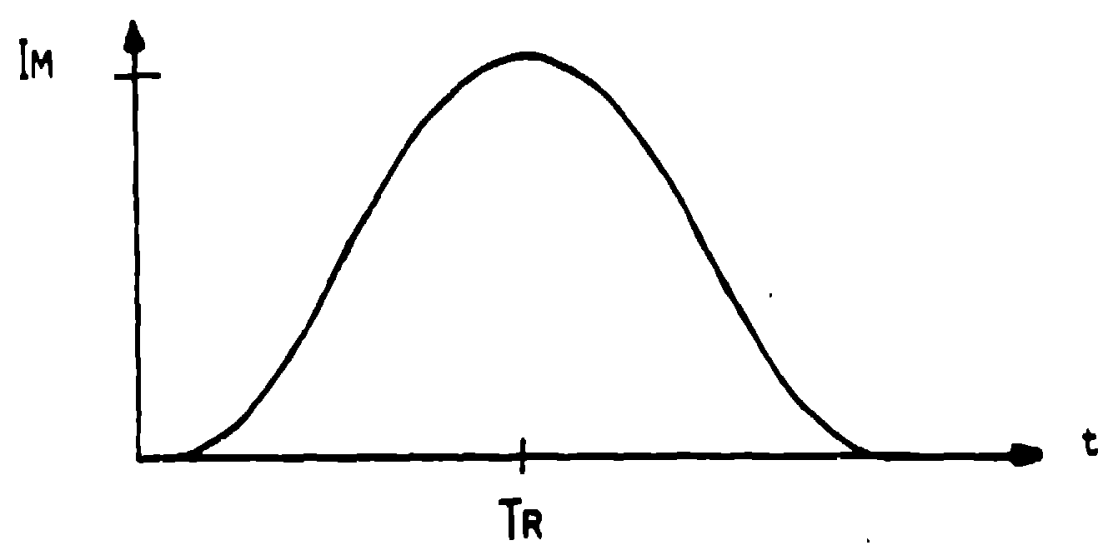

$$
\begin{array}{ll}
I_{M}=\frac{V_{0} \pi C}{2 T_{R}} & V_{0}=\frac{\pi L I M}{2 T_{R}} \\
V_{0}=\frac{I_{M} 2 T_{R}}{\pi C} & T_{R}=\frac{V_{0} \pi C}{2 I M} \\
C=\frac{2 T_{R} I M}{V_{0} \pi} & L=\frac{2 V_{0} T_{R}}{\pi I M}
\end{array}
$$

ED5380.EL 
FIGURE 23: SIMPLIFIED EXIIMER LASER DRIVER

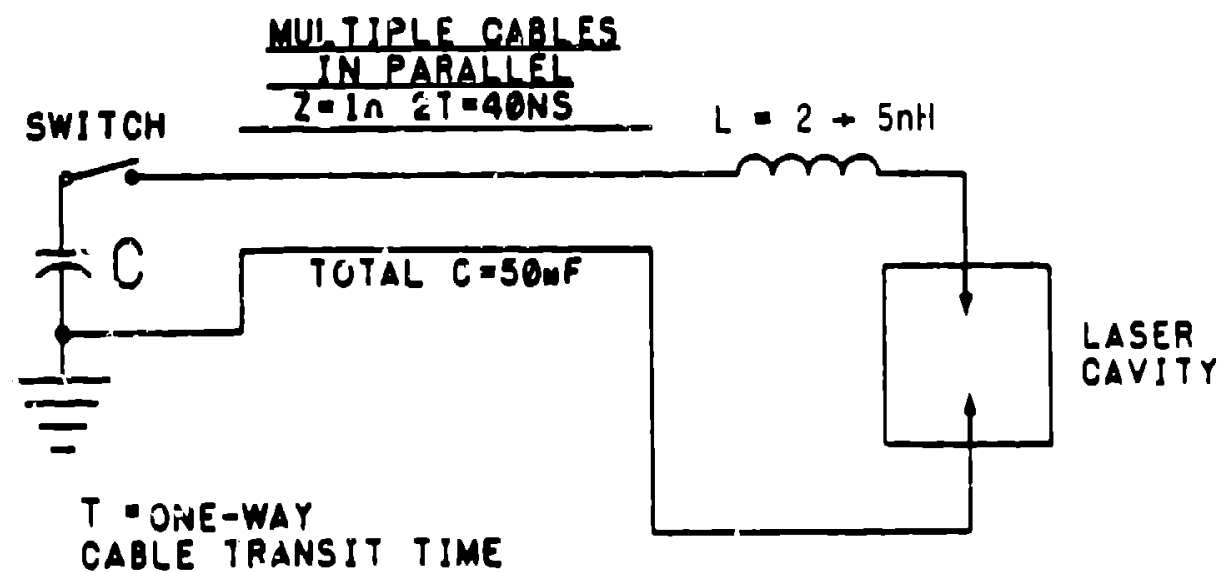

ED5380.[L 
It is not unusual to see them go from many ohms to milliohms, making the maintenance of a constant $v_{L}$ (which determines the excitation efficiency of the sjstem) extremely difflcult. Unilke the carbon dioxide laser, these discharge-pumped systems are quite unstable plasmas, so that the impedance of the krypton (or argon, xenon, etc.) helium, and fiuorlie mixtures decreases monotonically with time. These notes highlight the most extensive engineering siudy parformed to date on the electr,cal characteristics of these lasers, ${ }^{9}$ and time permits sketching only some of the interesting properties of these loads. Figure 24 schematically lllustrates the type of Excimer laser of intarest here. Energy is stored in the drtver capacitor $D$ and transferred into the cable capacitance $C$ during and after the closure of the sparix gap or thyratron switch $S$. The cable PFN generally has an impedance of 0.5 to $1 \Omega$ and a discharge time approximately equal to the sum of the cavity time to break down plus the time to termination of the laser puise. (This is close to the time the current takes to decay through zero.) As the swltch closes, there is a permisstble butld-up :ime. Inttially, the gas mixture is prefonized by one of several means, here by an array of sparks $P$ along the electrodes $E$. After a short delay, the switch $S$ is closed and the voltage on the electrodes bullds up from zero to break juwn in abou: $80 \mathrm{~ns}$. Then a large current flows through the low-Inductance load ( $L$ is apprisximately $2 \mathrm{nH}$ ). The most signiflcant pioblem in this system is the rapid de:-odse in the load impedance with time, clearly indleating that conventional PFN design techniques are inapproprlate to achieve the theoretically high efficlencles. To date, efflclencies in excess of $1 x$ have been achleved at energles of $=1 \mathrm{~J}$. The major difflculty with this system is that when the switeh eloses it joes so with a time constant, so the voltage on the electrodes has some bulld-up proflle, elther inductance $11 \mathrm{mited}$ or switch-iesistive phase 1 imited. Another major difflculty here is, ie current unavallahility of lumped elements with parasitic inductances sufficiently low to allow the synthesis of timeVarying PFNs required in this application. Devising techniques to effect such notworks or transrilssion lines, whatever may be the highest pumping efficlency drtveis for these ijstems, remains one of the more difficult power conditioning englneerting problems today.

ED5380.EL 
DISCHARGE CIRCUITS AND LOADS

LECTURE 5

42

FIGURE 24: TYPICAL EXCIMER LASER

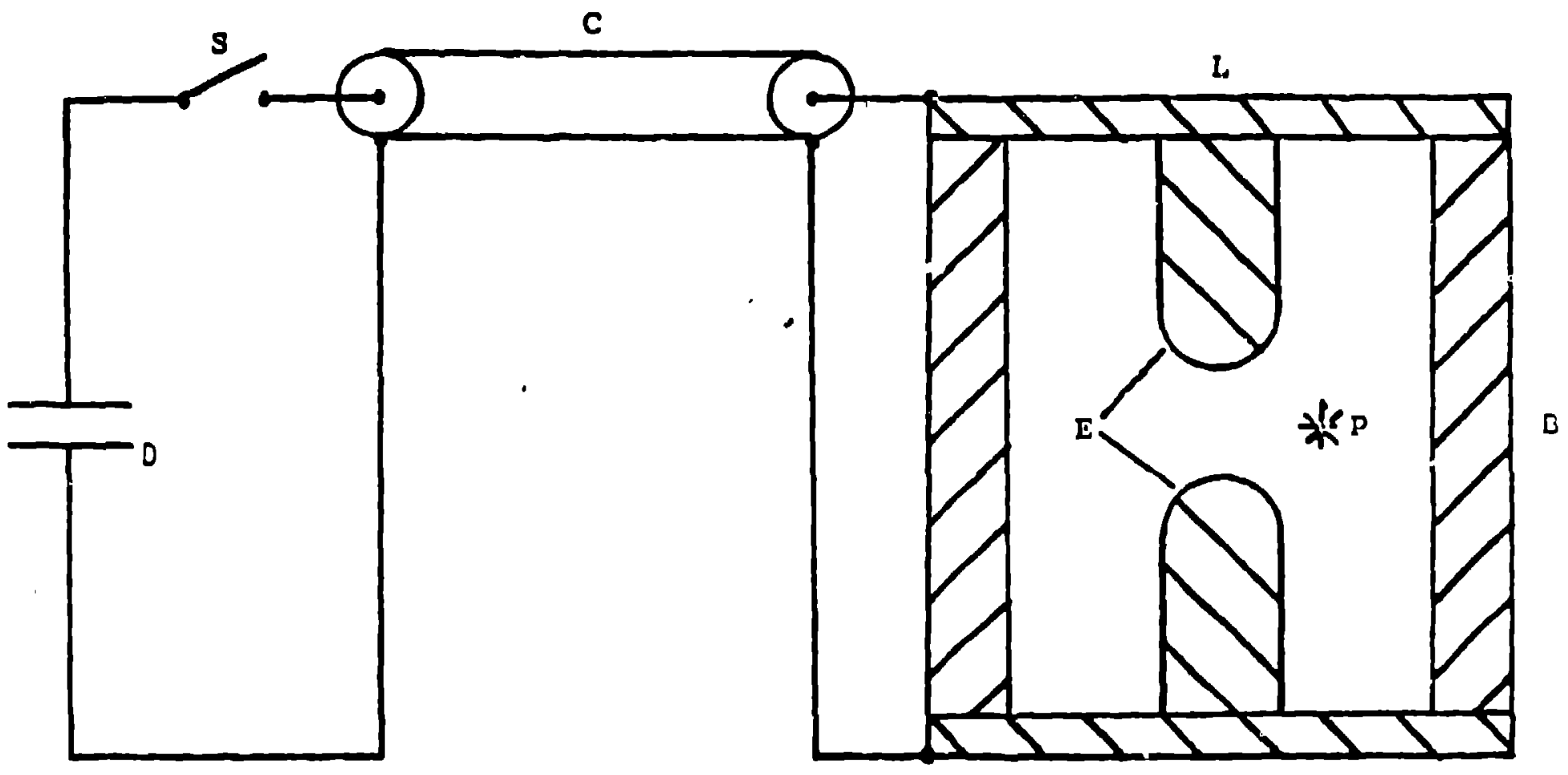

Typical Exciter Laser. D-drivor capacitor: S- switch; C- cable PFN; L- aluminum plate; E- electrodes; P- prelonization source; B- rigid dialectic body

Ref. 9

E05380. EL 
In these systems, the closure times of switches currently avallable are around $20 \mathrm{~ns}$, significantly affecting the bulld-up times on the cavity electrodes and adding to the energy losses in the discharge loop. Advances in pulse-charged, very low inductance thyratrons and spark gap switches may well make long-life laser's of this class a reality. The remaining challenge will be to design and construct low-inductance, inverse-dlode systems to protect the thyratron switches under conditions of laser cavity arcing.

Flgure 25 shows that for a KrF laser there is a voltage build-up uritil the discharge turns on. The current bullds up to peak value while the voltage is decreasing. This is undesirable because the voltage must stay above a threshold ievel for optimal excitation kinetics. This threshold level is, unfortunately, rather high. Most of the energy deposited in the system is Inefficient in pumping the laser. Ideally, a time-varying PFN is needed that has tne reciproca? of the impedance of the discharge with time down to levels of $=50 \mathrm{~m} \Omega$. In contrast to this, typical extended-foil capacitors have an internal resistance of $=25 \mathrm{~m} \Omega$.

Figure 26 also shows the predicted power vs time and the predicted impedance vs time. 9 The agreement with the model is quite good.

\section{B. Flashlamp Loads}

A flashlamp is a glass tube with two electrodes, containing xenon, krypton, or some other gas mixture at rather low pressures (F1g. 27). Assume a length 1 and a dianeter $d$. Normal flashlamps are driven by long (multimicrosecond) pulses; there is very little concern about switch losses and they can even be driven with silicon-controlled rectiflers. Empirically, it has been shown that the lamp voltage is some constant times the square root of the current through $1 t .10$

E05380.EL 
FIGURE 25: TIME HISTORY OF CIRCUIT AND SYSTEM PAR.AMETERS IN THE DISCHARGEPUMPED KrF $\star$ LASER

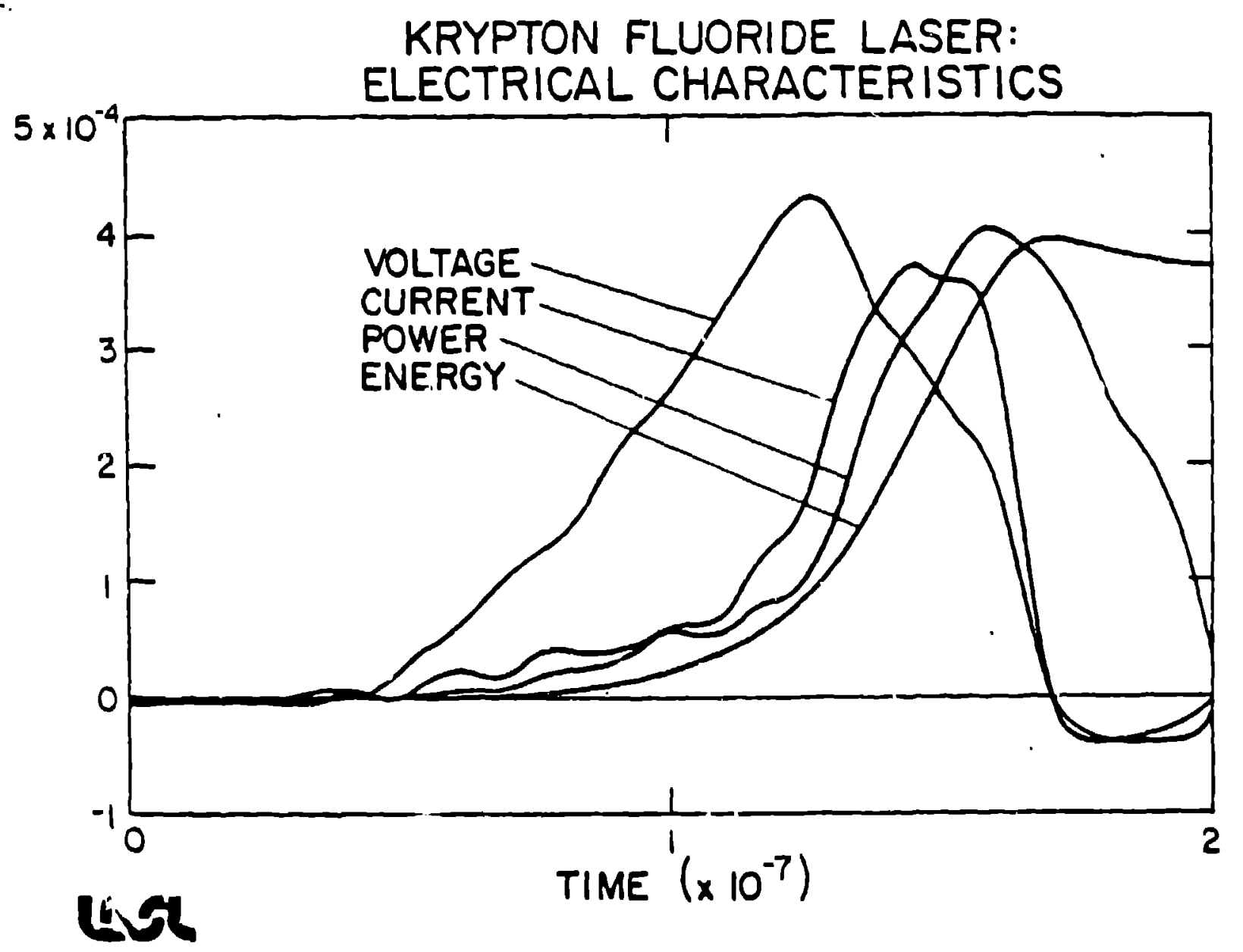

Ref. 9 
FIGURE 26: COMPARISON OF PREOICTED AND MEASURED POWERS AND IMPEDANCES IN THE DISCHARGE-PUMPED KrF* LASER
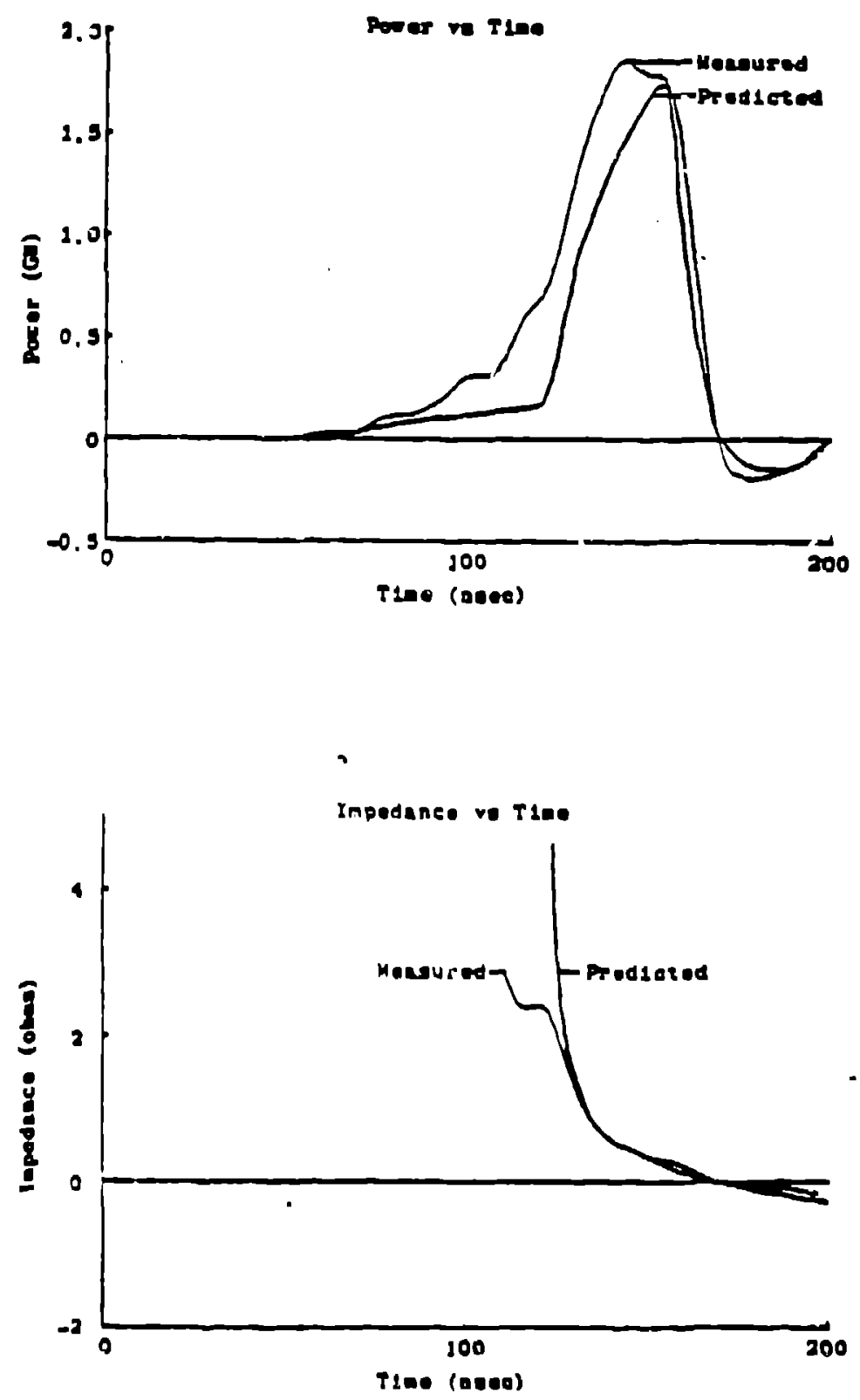

Ref. 9 
FIGURE 27: FLASHLAMP LOADS

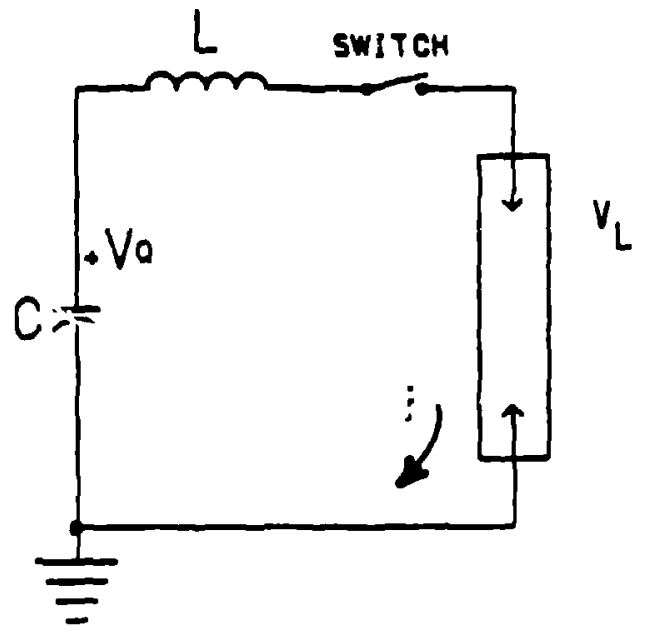

FLASHLAMP: of length $1 \mathrm{~cm}$

Containing Xenun or krypton

Pulse widths are typically 5 to 125 us so that switch losses can be neglected.

$$
V_{L}= \pm k /\left.i\right|^{l} \text { : Empirically determined }
$$

For small voltage reversals on $C$ and maximum energy transfer into the lamp in the flrst current cycle: (say $=20 x$ reversal as determined by the cost for $C$ for a given lifetime)

Then: 1. $k-1.3 \frac{1}{d}\left(\frac{p}{p_{1}}\right)^{2} \quad p_{1}=450$ torr for xenon

2. $U=V_{0}^{2}$ : Energy stored in capacitor.

3. Let $T$ - Pulse width (not FWHM but zero to zero of current). $\tau=\pi \sqrt{L C}$

4. $c^{3}=\frac{n .5}{9} \frac{U \tau^{2}}{k^{4}}=\frac{0.05 U \tau^{2}}{k^{4}}$

5. Check $U$ explosion $-6.8 \times 10^{4}$ Id $(L C)^{2}$. $50 \times$ probabllity
( $\uparrow>$ 10us)
$.3 .8 \mathrm{ld} \sqrt{\mathrm{t}}$
of explosion

Ref. 10 
Capacitor cost can be reduced by allowing a small, say 20x, reversal and designing for maximun energy transfer in the first current half cycle. If the light output of the lamp and the energy to be deposited in the lanp are known, the explosion limits for relatively long pulses can be determined. When the energy stored in the capactior is equal to the determined energy, there is a $50 x$ chance that the 1 amp w111 blow up. In most eircuits, it has been found that the longer lamps can be operatad near the explosion ilmil. 10

The most conventent way to trigger a flashlamp is with a sertes injection trigger transformer, usualiy on the ground end. This generates a pulse that exceeds the self-break voltage of the lanp and the lamp turns on. The fluctuations in the breakdown time can be significantly reduced by overvolting the lamp by a factor of 2 .

\section{Carbon Oloxide Laser Load}

There are two $\mathrm{k}$ inds of $\mathrm{CO}_{2}$ lasers: electron beam lasers and TEA lasers. The latter are simtlar to the Excimar laser, wherein their impedance decreases with time, but at a slower rate. The $\mathrm{CO}_{2}$ lasers with electron-beam-controlled discharge systams, for example, bastcally act as resistive loads with some iurn-on voltage. The gas discharge voltage can be provided by a Marx bank. If the pumping voltage wave form is altered to r'se more quickly the gain rises fastor, permitting more energy to flow out of the system for shorter optical pulses into it. Exper imenters have looked into, type $C$ PFN, with two sections (two $L$ and $C$, one each per section in the PFN) and have darived the voltage pulse shown in Fig. 28. This worked very well." 
FIGURE 28: CARBON DIOXIDE LASER LOADS

Electron beam controlled discharge

- pure resistive load compared to diode magnetron type of load

- can use type C PFN in Marx stages

- large units: $Z$. $3 \Omega$ for $2.5 \mu s$ discharge times

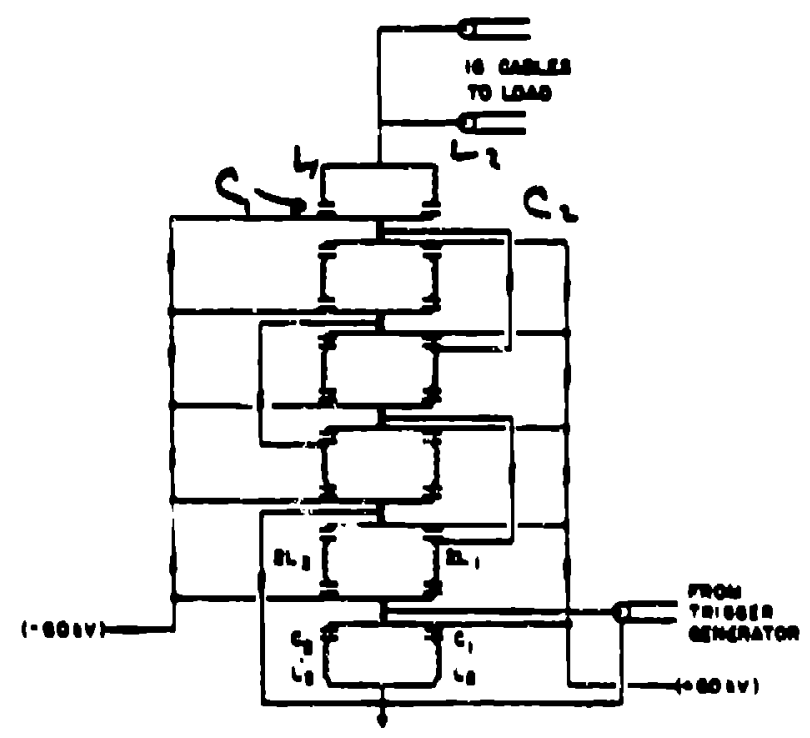

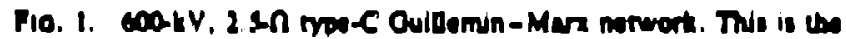

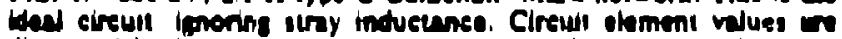

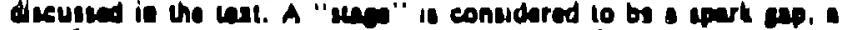

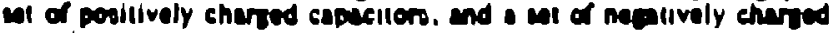
apadien.

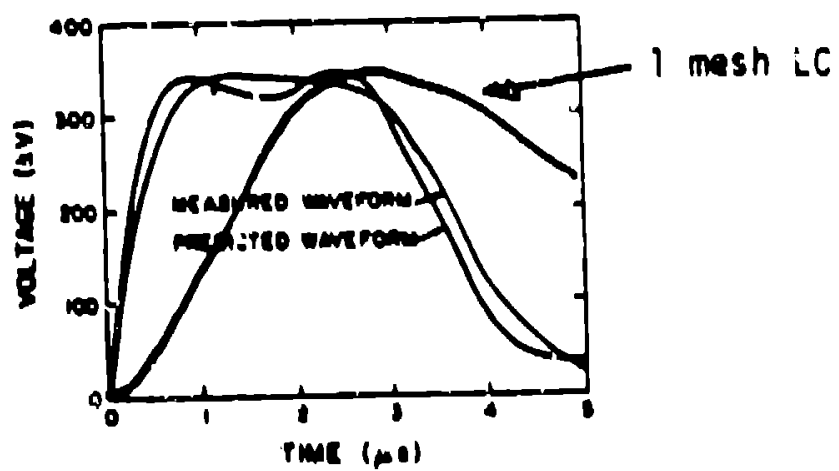

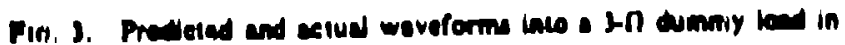
in PrN unh.
PER STAGE: TYPE C PFN

$L_{1} \cdot 0.63 C_{1} 20^{2}$

$L_{2} \cdot 6.5 C_{2} 20^{2}$

$C_{1}=0.40 \frac{T}{20}$

$c_{2}=0.042 \frac{T}{20}$

Defining $?, V_{\text {pk }}$ and $U$ stored defines all the particular components.

then

$$
\begin{aligned}
& C_{1}=8.6 \mathrm{~F} \\
& C_{2}=0.58 \mathrm{~F} \text { for } \\
& L_{1}=220 \mathrm{~F} \quad 20=2.5 \mathrm{~A} \\
& L_{2}=235 \mathrm{~F}
\end{aligned}
$$

Advantages for Reststiva Load:

1. $V_{\text {pk }}$ per stage times $n \cdot V_{L}$

2. Stray L in connection loop affects risetime hut not peak power.

3. Wavaform readlly changed. $\therefore$ Can use with tima varying loads. 
The TEA lasers are like HF and KrF lasers that are discharge pumped. They can be made to work very well at high-repetition rates, but everything that has been sald about the KrF laser can be sald about TEA lasers, mult1plying the time-scale of excitation by a factor of 10. The TEA lasers also have a smaller decrease in impedance with time, compared to KrF lasers the ratio is considerably less.

\section{D1scharge-Pumped Hydrogen Fluortde Laser Load}

The HF lasers are attachment-dominated and the Impedance decreases with time (Figs. 25 and 30 ). impedance was measured as a function of current in klloamps for different pressures of the gas (Fig. 31). To design this particular system, one must choose a pulse width less than the arcing pulse duration $(=0.25 \mathrm{us})$. Eyen if the electric fleld is kept constant, the gas heats with time unt 11 it exper lences thermal breakdown. This is a common characteristic power-loading limit of dil lasers.

XIII. SUMMARY

Generally speaking, with the exception of electron-beam systems, lasers all have decreasing impedances with time. This presents a challenging area for research to provide high-efflclency lasers with electrical PCS drivers optimized to meet the load excitution kinetics requirements. 
IIIGURE 29: DISCHARGE-PUMPED HYDROGEN FLUORIDE LASER LOAD

1. Electrical drive similar to KrF* laser discussed before.

2. From expartment: Impedance decreases with increasing discharge current: A time-varying load.

-Take $Z$ at peak current to design PFN with peak voltage determined from a scaling experiment.

-Design PFN width for optimum pumping and pulse termination before the onset of arcing ( = $300 \mathrm{~ns}$ for a laser electrode spacing of $5 \mathrm{~cm}$ )
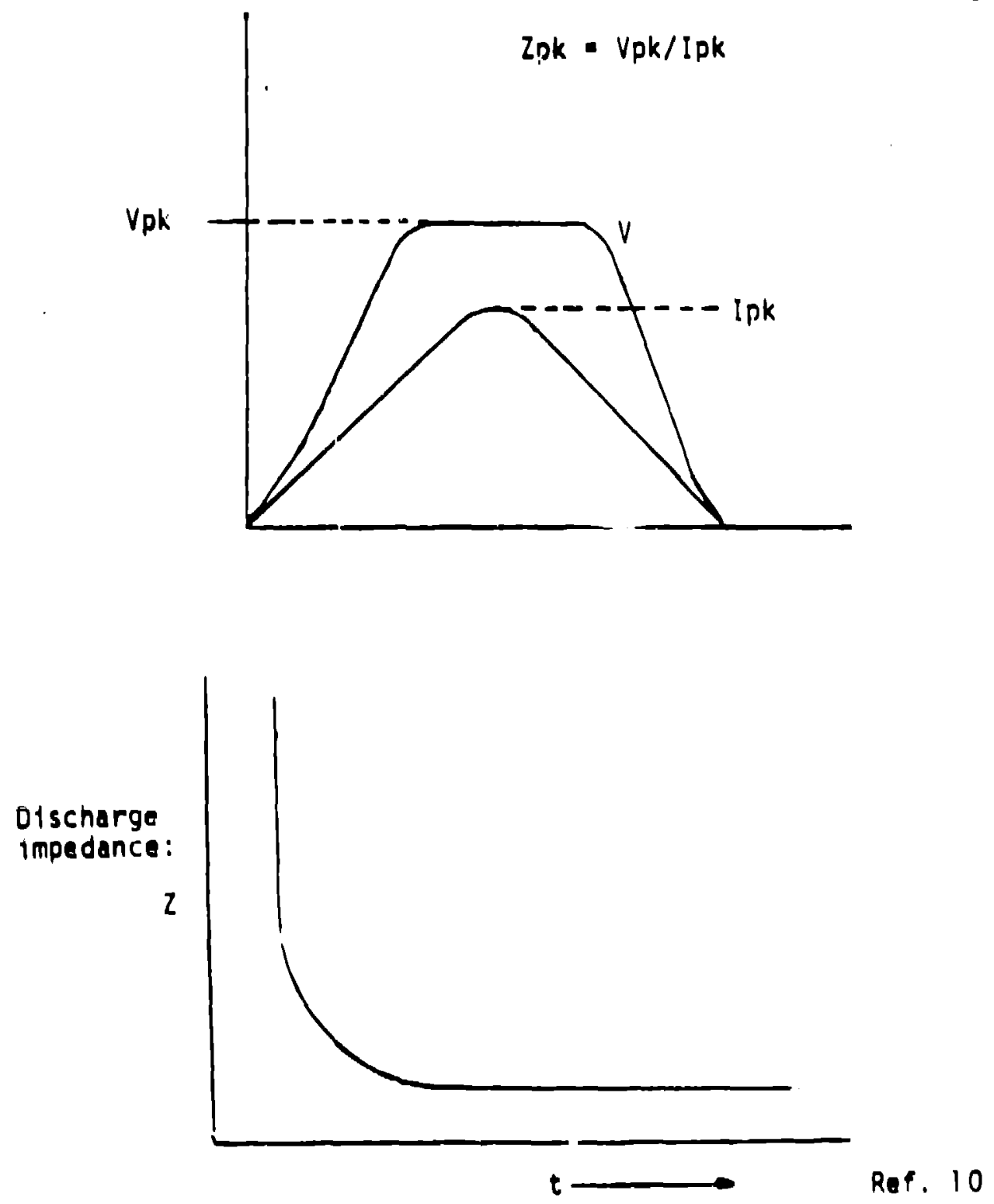
FIGURE 30: OISCHARGE-PUMPED hIYDROGEN FLUORIDE LASER LOAD

\section{Results of the calculations}

-Used NET 2 program and incorporated $L$ of each capacitor as part of the PFN. Type E-C hybrid PFN could be designed analytically but far more cost effective to use computer.

4. Short circult ringing tests:

a. short cavity

b. from ringing following may be determined

$$
\begin{aligned}
& I_{p k} a I_{0} e^{-R / L} \cdot t \\
& \therefore \operatorname{lnI}{ }_{p k}^{+}=\ln \text { IO }-\frac{R}{[} T / 4 \\
& \operatorname{ln!} !_{p k}^{-} \cdot \ln 10-\stackrel{R}{[}_{3 \tau / 4}
\end{aligned}
$$$$
\tau=2 \pi \sqrt{L C}
$$

Subtract

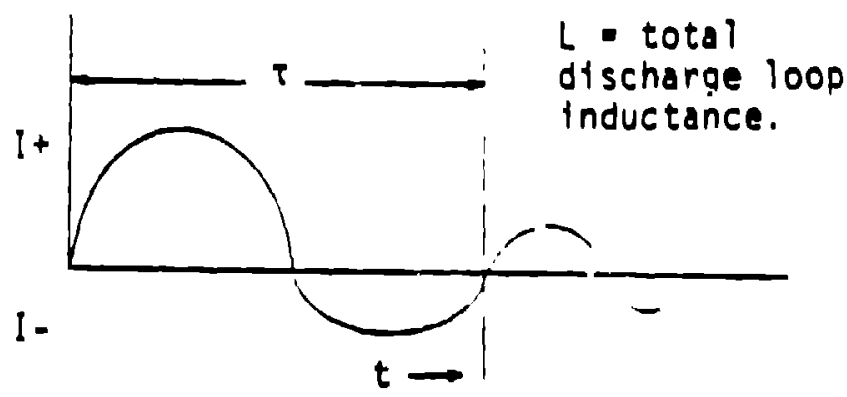

$$
\ln I_{p k}^{-}-\ln I_{p k}^{+}-\ln \left(I_{p k}^{-} / I_{p k}^{+}\right)=\frac{R}{4 L} \cdot(3-1)+-R T / 2 L
$$

- $\frac{R}{2 L} \cdot 2 \pi \sqrt{L C}=\pi R \sqrt{C / L} \cdot$ In (Damping ratio)

$\therefore$ obtain "L" and "R"

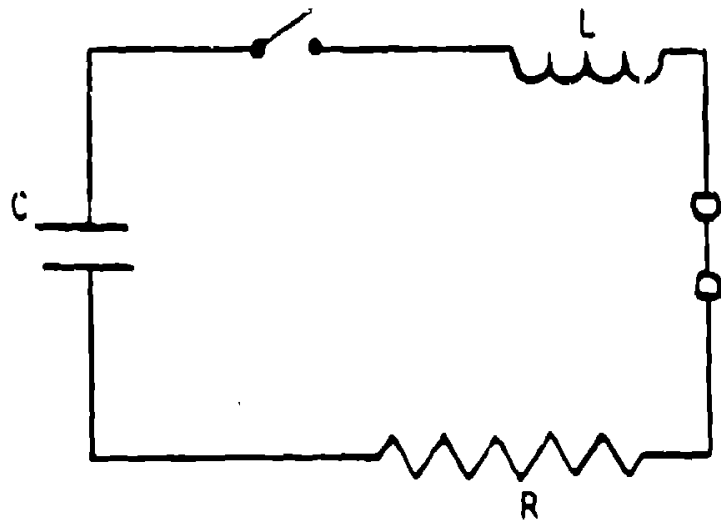

SHORT CIRCUIT LASER CAVITY

RINGING EXPERIMENT

Ref. 10 
FIGURE 31: APPARENT IMPEDANCE OF THE DISCHARGE-PUMPED HYOROGEN FLUORIDE LASER LOAD

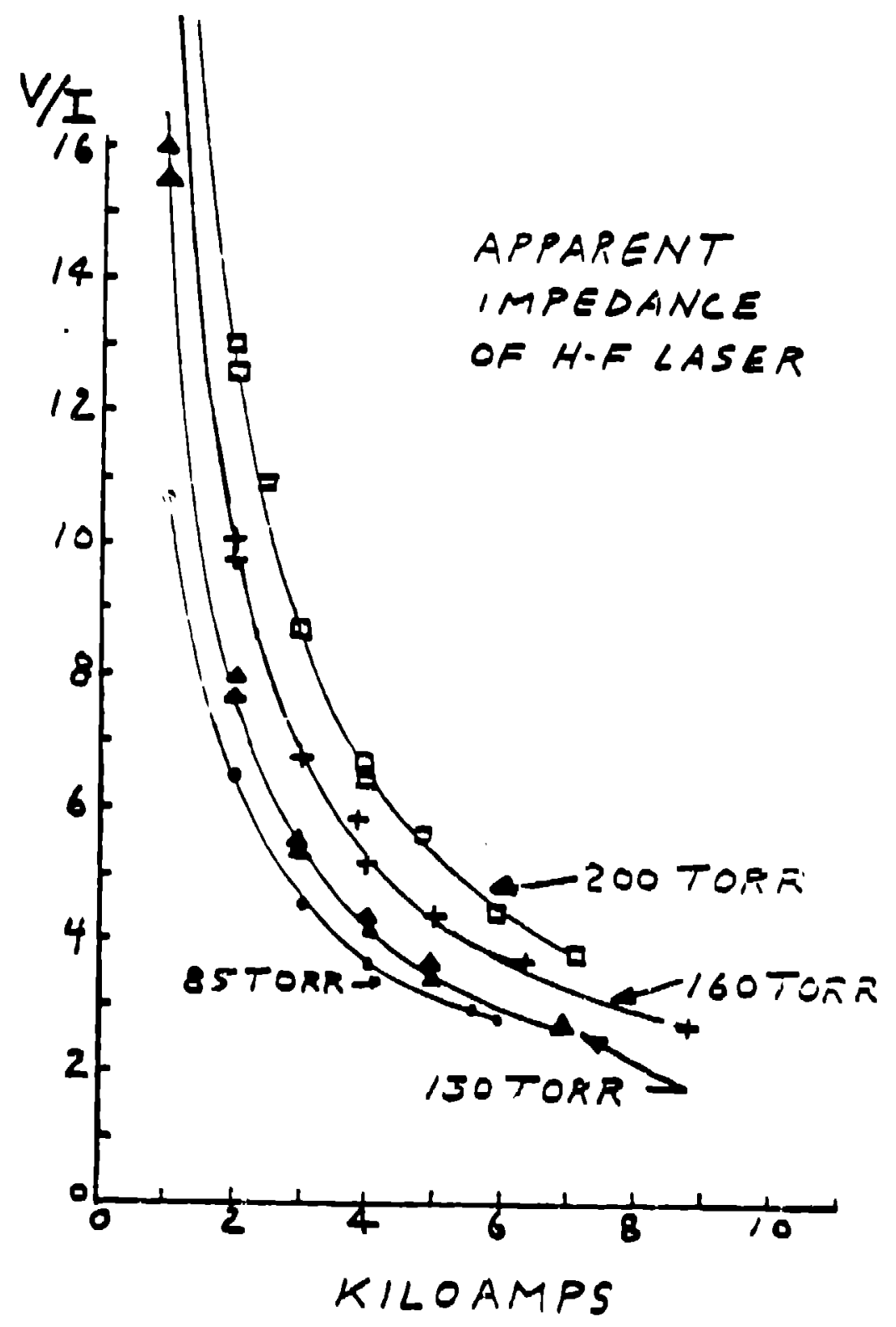




\section{REFERENCES}

1. G. N. Glasoe and J. V. Lebacqz, Pulse Generators (McGraw-Hill, New York, 1948).

2. W. J. Sarjeant, "Energy Storage Capacitors," Lijil Report No. LA-UR-79-1044, August 1979. (See also Lecture 4, Appendlx of EECS596 "High Voltage/Pulse Power Technology," UNM graduate course).

3. T. P. Sorensen and V. M. Ristic "R isetime and Time-Dependent SparkGap Resistance in Nitrogen and Helium," Journal of Applied Physics, Vol. 48, No. 1, January 1.977, pp. 114-117.

4. W. L. W11lis, "Spark Gaps," Los Alamos Sc fent if ic Laboratory Report No. LA-UR-80-634, (see also Lecture 6 of EECS596 "High Voltage/Pulse Power Technology," UNM graduate course).

5. W. J. Sarjeant and W. C. Nunnally "A Kllohertz Trigger System for Multichanneling a 100-kV Mid-plane Spark Gap," Los Alamos Scientific Laboratory Memor anduin No. E-4-79-101, March 5, 1979.

6. A. E. Greenwood, Electrical Transients in Power Systems, Wileyintersctence, New York, 1971).

7. G. Metzger and J. P. Vabre, Transmission Lines with Pulse Excitation, (Academic Press, New York, 1969).

8. "Hydrogen Thyratrons -- Theory and Appi ations," General Electric. Technical Literature.

9. R. R. Butcher, "A Comprehenstve Study of Excimer Laser Systems," Los Alamos Sclent if tC Laboratory thesis report LA-7329-T, June 1978.

10. W. L. Wtllis, unpublished data.

11. K. B. Rlepe, "High-Voltage Microsecond Pulse-forming Network," Rev. Sclence Instrumentation, Vol. 48, No. 8, August 1977, pp. 1028-1029. 